\title{
CloudSat-constrained cloud ice water path and cloud top height retrievals from MHS 157 and $183.3 \mathrm{GHz}$ radiances
}

\author{
J. Gong ${ }^{1,2}$ and D. L. Wu ${ }^{2}$ \\ ${ }^{1}$ University Space Research Association, Columbia, MD, USA \\ ${ }^{2}$ Climate and Radiation Branch, MC 613.2, NASA/Goddard Space Flight Center, Greenbelt, MD, USA \\ Correspondence to: J. Gong (jie.gong@nasa.gov)
}

Received: 29 May 2013 - Published in Atmos. Meas. Tech. Discuss.: 4 September 2013

Revised: 13 May 2014 - Accepted: 14 May 2014 - Published: 26 June 2014

\begin{abstract}
Ice water path (IWP) and cloud top height $\left(h_{\mathrm{t}}\right)$ are two of the key variables in determining cloud radiative and thermodynamical properties in climate models. Large uncertainty remains among IWP measurements from satellite sensors, in large part due to the assumptions made for cloud microphysics in these retrievals. In this study, we develop a fast algorithm to retrieve IWP from the $157,183.3 \pm 3$ and 190.3 GHz radiances of the Microwave Humidity Sounder (MHS) such that the MHS cloud ice retrieval is consistent with CloudSat IWP measurements. This retrieval is obtained by constraining the empirical forward models between collocated and coincident measurements of CloudSat IWP and MHS cloud-induced radiance depression $\left(T_{\text {cir }}\right)$ at these channels. The empirical forward model is represented by a lookup table (LUT) of $T_{\text {cir }}$-IWP relationships as a function of $h_{\mathrm{t}}$ and the frequency channel. With $h_{\mathrm{t}}$ simultaneously retrieved, the IWP is found to be more accurate. The useful range of the MHS IWP retrieval is between 0.5 and $10 \mathrm{~kg} \mathrm{~m}^{-2}$, and agrees well with CloudSat in terms of the normalized probability density function (PDF). Compared to the empirical model, current operational radiative transfer models (RTMs) still have significant uncertainties in characterizing the observed $T_{\text {cir }}$-IWP relationships. Therefore, the empirical LUT method developed here remains an effective approach to retrieving ice cloud properties from the MHS-like microwave channels.
\end{abstract}

\section{Introduction}

Ice clouds have profound impacts on the global energy budget (Stephens et al., 1990), hydrological cycle (Chahine, 1992), atmospheric structure (Ramaswamy and Ramanathan, 1989) and circulation (Richter and Rasch, 2008). Cloud ice water amount is one of the largest sources of uncertainty in quantifying cloud-climate feedbacks and sensitivities. For example, the mean cloud ice water path (IWP) ranges from 10 to $120 \mathrm{~g} \mathrm{~m}^{-2}$ in the tropics among a variety of global climate models (GCMs) in the most recent 20th century Coupled Model Intercomparison Project Phase 5 (CMIP5) runs (Li et al., 2012). Accurate cloud IWP measurements are critically needed to guide model developments and reduce model uncertainties.

However, observations of cloud ice have not met the requirement by climate models, showing several folds of IWP differences among various techniques (Wu et al., 2009; Eliasson et al., 2011). Until cross-instrument consistency is achieved, current cloud ice observations will allow too much variation in cloud properties and become insufficient for constraining the model physics (Waliser et al., 2009; Li et al., 2012). Difficulties for accurate IWP and microphysical measurements arise mainly from remote sensing in the presence of cloud inhomogeneity and sensitivity limitations associated with each technique. On one hand, large spatial and temporal variabilities in cloud microphysics make it difficult to compare ground-based measurements with remote sensing observations (Waliser et al., 2009). Hence, statistical representations of cloud microphysics are assumed or parameterized in order to enable satellite remote sensing (e.g., McFarquhar and Heymsfield, 1997). Even for simple optically thin cloud, there are still a great number of uncertainties 
in the assumptions made for the IWP retrieval. On the other hand, passive satellite sensors have limited penetration capability to observe thick and dense ice clouds from space. As a result, only partial columns of IWP (pIWP) can be measured by passive sensors, and the column bottom varies with atmospheric absorption, cloud amount, droplet size and phase, and cloud top height. These uncertainties about cloud column create additional errors in the IWP retrieval using passive sensors.

As an active sensor, CloudSat radar provides an unprecedented opportunity to measure the ice water content (IWC) profile and its vertical integral (i.e., IWP) globally since 2006. The CloudSat cloud ice retrieval still depends on the cloud microphysics constrained by in situ and ground-based observations (Austin et al., 2009). CloudSat data are confined in a narrow curtain $(\sim 1 \mathrm{~km}$ width) along the orbital track, and thus are used mostly for climatological and case studies. Like other A-train sun-synchronous satellites, it samples only two local solar times (01:30 and 13:30 LST) of the cloud diurnal cycle. However, CloudSat data still provide the best characterization of the vertical distribution of global cloud ice (Eliasson et al., 2011), and can be used to cross-calibrate other techniques, especially the passive sensors with limited vertical resolution. (Wu et al., 2009).

Passive nadir-viewing microwave techniques such as Advanced Microwave Sounding Unit-B (AMSU-B) and the Microwave Humidity Sensor (MHS) have an advantage over infrared/visible sensors in penetrating deeper into cloud layers to measure IWP. More importantly, MHS has a swath width of $\sim 2300 \mathrm{~km}$ to capture synoptic-mesoscale systems in motion as well as variabilities not captured from the curtainonly sampling by CloudSat. Instead of slicing a single vertical cross section of a hurricane, the entire cyclonic structure can be mapped out with one MHS orbit. Since 1998, satellites carrying instruments like AMSU-B and MHS have been operational and now fly across the Equator at more than eight local solar times every day, the mosaic of which can be used for cloud diurnal cycle studies. Moreover, at microwave frequencies ice scattering signals are approximately linearly proportional to cloud ice amount in the path, resulting in a relatively straightforward relationship between IWP and cloud-induced radiance depression (Wu et al., 2009). These advantages make nadir-viewing microwave sensors attractive for monitoring global long-term IWP.

Retrieval of IWP requires radiative transfer models (RTMs) or forward models that relate cloud ice to the measured radiance. The cloud ice models can be formulated either theoretically or empirically. RTMs are also widely used in climate models but primarily for calculating clear-sky radiative forcing from atmosphere gas, cloud, aerosol and surface. Although studies demonstrated the use of RTMs for IWP retrievals from AMSU-B/MHS channels, considerable uncertainties exist with RTMs in representing complex physical processes (e.g., land surface radiative fluxes, ice particle shape) and with oversimplified assumptions (e.g., plane-parellel atmosphere and cloud layers, cloud droplet size distribution, etc.). The errors in liquid drop size, surface emission/scattering, cloud layer height, and water vapor amount can all degrade the quality of the retrieved IWP. For example, the current operational IWP retrieval algorithm from Microwave Surface and Precipitation Products System (MSPPS), which is based upon a two-stream approximated radiative model solution (Zhao and Weng, 2002) at AMSUB 89 and $150 \mathrm{GHz}$ channels, was found to under-estimate IWP in comparison with other observations (Wu et al., 2009; Waliser et al., 2009; Eliasson et al., 2011; Chen et al., 2011). Contamination of cloud ice retrievals was also found over snowy/icy surfaces (Wu et al., 2009).

While further improvements are still needed for ice scattering calculation in the microwave RTMs, empirical forward models have been used for cloud retrievals (Holl et al., 2010). Empirical approaches establish some ad hoc relationships between cloud ice variables and radiance/reflectivity measurements from the data themselves. Such empirical forward models are developed from a finite ensemble of observations, and are therefore limited to specific conditions, environments and dynamic ranges of the cloud variable of interest. The algorithms are usually fast in the form of a look-up table (LUT) and bypass the complex microphysical calculation in cloudysky radiative transfer in individual cases. Empirical methods have also been used in surface remote sensing where land properties are too complicated to be modeled or validated (e.g., Pulliainen and Hallikainen, 2001).

In this paper, we develop an empirical model and retrieval algorithms for IWP using cloud-induced radiance depression $\left(T_{\text {cir }}\right)$ from MHS at $157,183.3 \pm 3$ and $190.3 \mathrm{GHz}$. The empirical forward model is obtained by regressing MHS $T_{\text {cir }}$ radiances on collocated CloudSat IWP and cloud top height measurements in the tropics. The sequential estimation method is then used to retrieve IWP for all MHS footprints. The instruments and methodology will be described in Sect. 2, followed by the detailed retrieval algorithm in Sect. 3. An evaluation of the retrieved products and the associated errors is going to be given in Sect. 4, followed by the summary in Sect. 5 .

\section{Instruments, data, and methods}

\subsection{Description of data sets and models}

The data sets used in this study are Level-1 brightness temperature $\left(T_{\mathrm{B}}\right)$ from MHS, ice water content (IWC) from CloudSat, and Modern Era Retrospective-Analysis for Research and Applications (MERRA) three-hourly analysis variables on a $1.25^{\circ} \times 1.25^{\circ}$ latitude-longitude grid. The two radiative transfer models used in this study are Joint Center for Satellite Data Assimilation (JCSDA) Community RTM (CRTM) and an ice scattering cloud radiance model (CRM). 


\subsubsection{MHS $T_{\mathrm{B}}$, IWP and historical issues}

MHS is a cross-track scanning radiometer aboard the National Oceanic and Atmospheric Administration (NOAA) satellite 18, 19, European Organisation for the Exploitation of Meteorological Satellites (EUMETSAT) Metop-A, and Metop-B, which is a slightly improved version of AMSUB onboard NOAA-15, 16, and 17. MHS makes 90 footprints (with a beam width of $1.1^{\circ}$ ) continuously in each cross-track scan and the outermost scan angle is $\pm 48.95^{\circ}$ from nadir. For NOAA-18, the MHS scan and satellite orbital altitude produce a nadir footprint size of $16 \mathrm{~km}$ at half-power field of view (FOV) and a swath width of $2200 \mathrm{~km}$. The FOV size and swath vary slightly among satellites due to different orbital altitudes. MHS has five microwave channels, which are 89, $157,183.3 \pm 1,183.3 \pm 3$ and $190.3 \mathrm{GHz}$ (for AMSU-B, the second and last channels are 150 and $183.3 \pm 7 \mathrm{GHz}$, respectively). For consistency, these channels are labeled as $\mathrm{CH \# 1-}$ $\mathrm{CH}+5$ hereafter. MHS $\mathrm{CH} \# 1, \mathrm{CH} \# 2$ and $\mathrm{CH} \# 5$ are vertically polarized, and the other two are horizontally polarized (for AMSU-B, all five channels are vertically polarized). The designed radiometric noises $(N E \Delta T)$ for $\mathrm{CH} \# 1-\mathrm{CH} \# 5$ are $0.22,0.34,0.51,0.40$, and $0.46 \mathrm{~K}$, respectively (John et al., 2012). The 89 and $157 \mathrm{GHz}$ are window channels, and those around $183.3 \mathrm{GHz}$ water vapor absorption line are designed to profile the atmospheric water vapor. Under clear-sky conditions, the peak sensitivity of these $183.3 \mathrm{GHz}$ channels occurs in the upper, middle and lower tropospheres, respectively. NOAA-15, 16, 17, 18 and 19 orbits drift slowly with time, while Metop-A and Metop-B are maintained at a sunsynchronous orbit with fixed Equator passing time (EPT).

For ice particle scattering measurement, the higherfrequency channels $(157,183.3$ and $190.3 \mathrm{GHz})$ work better for IWP retrievals because the Mie scattering is proportional to frequency to the fourth power. Scattering-based microwave cloud remote sensing has some unique properties as well as limitations. First, it penetrates deeper into ice clouds than IR and visible techniques for cloud ice measurements, but can become saturated for very optically thick clouds (Seo and Liu, 2006; Arriaga, 2000). In the case of saturation, only partial cloud ice column pIWP can be retrieved. As shown in Seo and Liu (2006), the window channels near $183.3 \mathrm{GHz}$ can penetrate a cloud layer with IWP as large as $10 \mathrm{~kg} \mathrm{~m}^{-2}$, which covers most of the IWP values observed by CloudSat. However, in the case of graupels, or frontal astrostratus clouds, saturation may occur (Arriaga, 2000). Saturation is also more prominent in the oblique views than nadir (where the line-of-sight path is longer).

Secondly, among all MHS/AMSU-B channels, $\mathrm{CH \# 3}$ is most sensitive to water vapor because it is adjacent to the $183.3 \mathrm{GHz}$ water vapor absorption line. The absorption from upper tropospheric water vapor, so-called "water vapor screening", prevents $\mathrm{CH} 33$ from seeing the surface and clouds in the lower troposphere. To some extent, $\mathrm{CH \# 4}$ has quite amount of water vapor screening and can observe some ice clouds, but remains little contaminated by the surface unless at dry, high latitudes. In other words, $\mathrm{CH \#} 4$ can be used to distinguish between surface and clouds in the situation where other channels have difficulties, as will be shown in Sect. 2.1.3.

Lastly, microwave radiances are dependent on scan angle at these frequencies. Under clear-sky conditions, the radiance may decrease with scan angle from nadir, as a function of the cosine of angle, due to the increasing path length at line of sight (LOS). This is similar to the $6.7 \mu \mathrm{m}$ IR channel where the longer LOS path gives a weighting function at a higher altitude, or cold temperature (Soden, 1998). Under the cloudy-sky condition, the radiance scan dependence may vary with cloud inhomogeneity as cloud size and distribution are often not homogeneous. In addition to the atmosphereinduced scan angle dependence, there are some instrument errors in all five channels that are scan dependent and asymmetric about nadir. These instrumental errors can severely degrade the quality of the retrieved IWP if not properly corrected. For example, there was a radio-frequency interference (RFI) problem in $\mathrm{CH} \# 3$ and $\mathrm{CH} 44$ of AMSU-B (Atkinson, 2001; Buehler et al., 2005), and gain variations/degredations are found in $\mathrm{CH} \# 3-\mathrm{CH} \# 5$ of AMSU-B on NOAA-16 and NOAA-17 (John et al., 2013). MHS exhibits smaller scandependent biases than AMSU-B, but suspicious behaviors have been reported for CH\#3 on NOAA-18 and NOAA-19 and Metop-A (John et al., 2013). The MHS instruments on NOAA-18 and Metop-A have so far shown the best overall radiometric calibration for all five channels. Since NOAA18 has the closest EPT with CloudSat, it is used in this study to develop the cloud ice retrieval constrained by CloudSat. The radiances from $\mathrm{CH} 33$ are not used because they are relatively noisier and provide little information on cloud ice. As in the main weather prediction centers, we use the Advanced Television and Infrared Observational Satellite Operational Vertical Sounder (ATOVS) and the Advanced Very High Resolution Radiometer (AVHRR) pre-processing package (AAPP, v7) developed by Numerical Weather Prediction Satellite Application Facilities (NWP SAF) to process the L1B radiance data to obtain the further quality-controlled and calibrated L1C data. In the NOAA-18 MHS L1C data we have not found any systematic instrumental error.

Weng et al. (2003) developed an algorithm to retrieve the IWP using ice scattering at 89 and $150 \mathrm{GHz}$, which is known as the NOAA operational IWP product. Their retrieval algorithm yields effective ice particle size and IWP with cloud top and base temperatures derived from simultaneous AMSUA channels. A considerable fraction of false cloud detection was found with this method, mostly over icy/snowy surfaces and on elevated topography (Wu et al., 2009). The NOAA IWP has been reported to have significantly low values compared with radar and IR measurements (Holl et al., 2010; Eliasson et al., 2011). As an extended product, rain rate is derived from the retrieved IWP with an empirical polynomial relationship (Ferraro, 2007). The operational NOAA IWP 
data, now integrated into the MSPPS in the CLASS website, will also be used in this study for comparisons.

\subsubsection{CloudSat IWC}

Launched into the A-train in April 2006, CloudSat has a $94 \mathrm{GHz}$ cloud profiling radar (CPR) to provide continuous cloud profiles along its nadir track. A CPR FOV size is $1.3 \times 1.7 \mathrm{~km}$. The cloud ice water content (IWC) product from 2B-CWC-RO (R04) is used in this study, which assumes a gamma size distribution of cloud ice particles. The CloudSat IWC retrieval is limited when the temperature is above $0^{\circ} \mathrm{C}$; so is the liquid water content (LWC) retrieval at temperatures below $-20^{\circ} \mathrm{C}$. Between 0 and $-20^{\circ} \mathrm{C}$, IWC and LWC are retrieved separately and linearly interpolated to the intermediate temperature range (details of the algorithm can be found in Austin et al., 2009). Thus, large uncertainties are expected for this mixed-phase cloud regime, and/or in the ice cloud cases with large snow/graupel particles present. The vertical resolution of the IWC profile is $250 \mathrm{~m}$. In our study, we interpolate it vertically to an evenly spaced grid ( $250 \mathrm{~m}$ resolution), and integrate the IWC between surface and $19 \mathrm{~km}$ to compute the total IWP. We also integrate the IWC profile from different bottom heights to represent the pIWPs measured by MHS channels better. Compared with Holl et al. (2010), who used the CloudSat total column IWP product, our IWC integration approach is more meaningful for comparison with pIWP seen from MHS water vapor channels, although the pIWP value is calculated on a profile-byprofile basis. Hereafter, we use IWP as the abbreviation of pIWP in our study to represent the MHS cloud ice column.

CloudSat IWC has been validated with in situ, groundbased and other satellite IWC measurements (e.g., Austin et al., 2009; Wu et al., 2009; Protat et al., 2009). The uncertainty is claimed to be up to $40 \%$ (Austin et al., 2009), which is much smaller than the divergences among various satellites and models, the latter of which often exceed $100 \%$ (Waliser et al., 2009; Eliasson et al., 2011). In this study, we treat CloudSat IWP as the "truth" to constrain the retrieved MHS IWP difference relative to that of CloudSat. Moreover, since microwave penetrates much deeper into ice clouds than IR/VIS channels, we expect our CloudSat-constrained algorithm to yield a better retrieval at large IWP values.

\subsubsection{Radiative transfer models (RTMs) and computation of $T_{\text {cir }}$}

The first step in cloud ice retrieval is to determine ice cloudinduced brightness temperature $T_{\text {cir }}$ from raw radiance measurements (Wu et al., 2009, 2014). In this study, $T_{\text {cir }}$ (cloudinduced radiance) is defined as the difference between the measured radiance, $T_{\mathrm{B}}$, and modeled clear-sky background (also called "cloud-cleared radiance"), $T_{\text {ccr }}$ :

$T_{\text {cir }} \equiv T_{\mathrm{B}}-T_{\mathrm{ccr}}$
$T_{\text {cir }}$ also serves as a critical variable for cloud detection since every measurement has an uncertainty that may lead to a false alarm. $T_{\text {cir }}$ error is largely affected by uncertainty in the estimated $T_{\mathrm{ccr}}$. Various methods have been developed to improve the accuracy of $T_{\text {ccr }}$ estimation. Generally speaking, $T_{\text {ccr }}$ can be obtained using statistical differences between cloudy and clear skies (Wu et al., 2005), or using the radiative transfer model to estimate the clear-sky background from the current atmospheric state. Here we use the second approach with the best estimate of local atmospheric state variables (e.g., temperature, pressure, water vapor, ozone) and surface conditions (e.g., surface temperature, surface type) from a MERRA three-hourly assimilation data set from interpolation of adjacent grid points and closest local time. We allow relative humidity to exceed $100 \%$ in computing clearsky radiation. We also used the MERRA six-hourly finer-grid analysis product and European Re-Analysis Interim (ERAInterim) data, but no statistically significant difference in $T_{\mathrm{ccr}}$ distribution is found among the results so far in the tropics and subtropics.

The JCSDA CRTM v2.0.5 model is employed to calculate $T_{\mathrm{ccr}}$. CRTM is a fast radiative transfer model that uses an advanced doubling-adding method (Liu and Weng, 2006) to compute the radiances and radiance Jacobians at the top of the atmosphere for various instruments, with wavelengths ranging from visible to submilimeter. It includes scattering calculations for cloud, aerosol, gas molecules and surface if specified. As the key backbone of data assimilation (DA) systems, the CRTM has incorporated most space-borne instrument information (e.g., spectral frequency, filter shape, and scan pattern), including AMSU-B and MHS. Therefore, it is also our objective to calibrate our cloud ice retrieval with this widely used CRTM for $T_{\text {ccr }}$ estimation so that the IWP outputs can be ready for the DA applications.

Figure 1 presents the probability density functions (PDFs) of $T_{\mathrm{cir}}, T_{\mathrm{ccr}}$ and $T_{\mathrm{B}}$ from a month's worth of MHS nadir measurements in the tropics. Warmer $T_{\mathrm{B}}$ values are mostly from the clear sky or surface, while colder $T_{\mathrm{B}}$ are the cases of ice clouds or snow/icy surfaces at a high elevation. The $T_{\mathrm{B}}$ PDFs all have a broad peak with a standard deviation $(\sigma)$ that is so wide that the empirical $3 \sigma$ cloud detection method (i.e., $T_{\mathrm{B}_{\text {peak }}}-3 \sigma<0$ for cloud detection) used by many previous studies does not work well when applied directly to the $T_{\mathrm{B}}$ data (e.g., McNally et al., 2006; Gong and Wu, 2013). On the other hand, the $T_{\text {cir }}$ PDFs have a smaller standard deviation because the CRTM-derived $T_{\text {ccr }}$ from MERRA data has removed a lot of clear-sky variability (Fig. 1a). The long PDF tail in the negative $T_{\text {cir }}$ values is a distribution of cloudy radiances. Ideally, a perfect $T_{\text {ccr }}$ model with perfect clearsky input would produce a singular peak in the $T_{\text {cir }}$ PDF at $0 \mathrm{~K}$, and all negative values that are smaller than the radiance noise would be classified as clouds. The uncertainty of $T_{\text {cir }}$ measurements, close to a Gaussian distribution, is reflected in the PDF spread near zero, especially in the positive half of the PDF. The ability to separate between cloudy and clear 

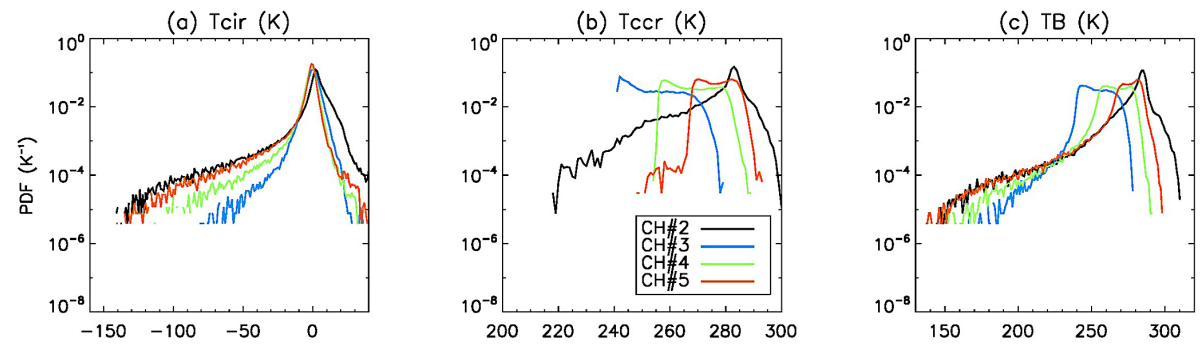

Figure 1. Probability density functions of $T_{\text {cir }}(\mathbf{a}), T_{\mathrm{ccr}}(\mathbf{b})$ and $T_{\mathrm{B}}$ (c) for $\mathrm{CH \# 2}$ (black), CH\#3 (blue), $\mathrm{CH \# 4} \mathrm{(green)} \mathrm{and} \mathrm{CH \# 5} \mathrm{(red).} \mathrm{Samples}$ are from the NOAA-18 MHS nadir view during August 2010 in the tropics $\left(\left[25^{\circ} \mathrm{S}, 25^{\circ} \mathrm{N}\right]\right)$.

radiances is characterized by this standard deviation $\sigma$, which can be computed from this portion of PDF.

However, the CRTM does not always improve cloud detection. For example, the width of the CH\#2 $T_{\text {cir }}$ PDF is not much narrower than that of $T_{\mathrm{B}}$, indicating limited skills of the CRTM in capturing the clear-sky variability. Large error in the calculated $T_{\text {ccr }}$ is found over mountains and arid areas, where it remains challenging for the CRTM to model surface contributions at $\mathrm{CH \# 2}$. When excluding all land cases, the $\mathrm{CH \# 2} T_{\text {cir }}$ can produce a PDF with a narrower width around zero (not shown). On average, the $T_{\text {cir }}$ error is $\sim 5 \mathrm{~K}$ (one standard deviation), although it may vary from 7.5 to $10 \mathrm{~K}$. In the cloud ice retrieval later on, the generic value of $5 \mathrm{~K}$ is used for all channels. In addition to $T_{\text {cir }}$ standard deviation, we also calculate $T_{\text {cir }}$ bias for each MHS channel since the clear-sky PDF should peak at zero. We find that the CRTM has a cold bias $(\sim 2 \mathrm{~K})$ at $157 \mathrm{GHz}$ (see Appendix B for details), whereas the bias is negligible for other channels (Fig. 6).

Moreover, Fig. 1a also reveals the dynamic range and penetration depth of the four MHS channels in measuring cloud ice. $\mathrm{Ch} \# 2$ penetrates deepest into clouds. Benefitting from its low frequency $(157 \mathrm{GHz})$ at which cloud scattering and water vapor absorption is lowest among the MHS channels, it produces the longest cloud PDF tail (black line in Fig. 1a). On the other end, $\mathrm{CH \# 3}$ has the most absorption from water vapor, showing the smallest $T_{\text {cir }}$ dynamic range. It has a slightly broader distribution in the positive half of $T_{\text {cir }}$ PDF,

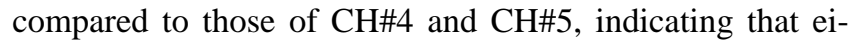
ther the upper-tropospheric water vapor from MERRA or the CRTM calculation at $\mathrm{CH \# 3}$ contains greater uncertainty.

Two popular operational RTMs are also used to explore how the observed $T_{\text {cir }}$-IWP relationship is simulated by models. These two RTMs are CRTM, and a multi-stream "cloudy-sky radiance model" (CRM) that is currently used by the Microwave Limb Sounder (MLS) team to retrieve ice cloud properties (Wu and Jiang, 2004). They both show a certain lack of ability to capture the observed $T_{\text {cir }}$-IWP relationship, which results in large biases in data assimilation and increases the uncertainty of IWP retrieval (Appendix C).

\subsection{Collocated and coincident MHS-CloudSat measurements}

Collocated and coincident measurements (collocations hereafter for briefness) are the incidences where two or more sensors observe the same location at the same time. These measurements provide useful pairs for instrument calibration (e.g., John et al., 2012), cross-validation of a particular variable (e.g., Wang et al., 2010), or development of new retrieval methods (e.g., Lamquin et al., 2008). In this paper, we will be focusing on the last application.

The requirements for collocated-coincident measurements may vary, depending on the variability of the specific variable. Since most of the atmospheric state variables (e.g., wind, temperature, humidity) change relatively slowly and continuously with space and time compared to fast processes like clouds, their requirements for collocation and coincidence should be a bit more relaxed and the allowed windows for space and time should be consistent. In other words, the uncertainty of collocation due to spatial variations should be comparable to one of coincidence due to temporal variations. Another factor in defining the requirements for collocation and coincidence is to assure enough samples for statistics. For the A-train sensors, sample size is usually not a problem. On the other hand, such a near-perfect collocation is rare between radiosonde and Global Positioning System (GPS) measurements (Sun et al., 2010). Neither occurs frequently for two satellites that run in different orbits. Adjustment of the collocating criteria becomes necessary and important in these situations.

In this study we use NOAA-18 measurements to find collocated-coincident cases with CloudSat because NOAA18 has the closest LST to CloudSat orbit among all operational satellites with the MHS/AMSU-B instruments (Holl et al., 2010). The requirements for collocation and coincidence are $10 \mathrm{~km}$ in space and $15 \mathrm{~min}$ in time, which yield a total of $6 \times 10^{5}$ MHS samples in the tropics $\left(25^{\circ} \mathrm{S}\right.$ and $\left.25^{\circ} \mathrm{N}\right)$ from June 2006 to March 2011. Holl et al. (2010) obtained one order of magnitude more collocated NOAA18-CloudSat measurements with a requirement of the same time difference but $15 \mathrm{~km}$ in distance, of which the number increase is roughly proportional to the area differences between the two 


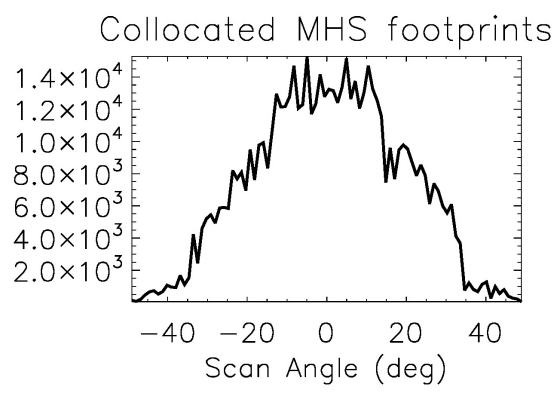

Figure 2. Total number of collocated and coincident MHS footprints as a function of scan angle between June 2006 and March 2011.

distance criteria. The sensitivity of the retrieval algorithm to the choice of collocation criteria will be discussed in the next section.

Because of the close orbits between NOAA-18 and CloudSat, the number of collocated measurements peaks at the MHS nadir angle and drops off similarly at the left and right view angles (Fig. 2). There is no significant scan angledependent sampling bias, which would be a factor to consider in the derived $T_{\text {cir }}$-IWP relationship. The number of collocations decreases sharply at oblique views with scan angle $\theta>35^{\circ}$, which may affect the statistical significance of the derived $T_{\text {cir }}-$ IWP relationship.

In the case of highly inhomogeneous clouds, larger uncertainty is expected for the IWP within MHS FOV, as CloudSat footprints cover at most $6.7 \%$ of the area of an MHS footprint. As a matter of fact, multiple CloudSat cloud profiles often correspond to an MHS footprint because the CloudSat footprint $(\sim 1.5 \mathrm{~km})$ is much smaller than the spatial range of the defined collocation. Thus, we average all the CloudSat IWP values within the collocated MHS FOV to represent the mean IWP for the MHS footprint. The same procedure is applied to calculate the mean cloud top height $\left(h_{\mathrm{t}}\right)$ at that MHS footprint, where each individual CloudSat $h_{\mathrm{t}}$ is obtained by searching for the highest level where IWC $>10 \mathrm{mg} \mathrm{m}^{-3}$.

\section{Empirical $T_{\text {cir }}$ model and IWP retrieval}

\subsection{Empirical $T_{\text {cir }}$-IWP relationships}

For nadir-viewing sensors like MHS/AMSU-B, negative $T_{\text {cir }}$ is caused primarily by ice cloud scattering instead of by emission. Mie theory shows that $T_{\text {cir }}$ is proportional to cloud IWP at microwave wavelengths and to the fourth power of frequency. As the ice cloud becomes radiatively thick, cloud self-extinction prevents $T_{\text {cir }}$ from penetrating deeper to sense the entire IWP, but rather, it has a sensitivity to pIWP. Hence, an empirical $T_{\text {cir }}$-IWP relationship is derived in the following format:

$T_{\mathrm{cir}}=T_{\mathrm{cir} 0} \cdot\left(1-e^{-\mathrm{IWP} / H}\right)$, where $T_{\text {ciro }}$ is the coldest $T_{\text {cir }}$ (i.e., saturation value) and $H$ is the parameter to determine where $T_{\text {cir }}$ becomes saturated. Both $T_{\text {cir0 }}$ and $H$ depend on frequency and can vary with cloud top height $\left(h_{\mathrm{t}}\right)$, instrument view angle, and temperature lapse rate $(\gamma)$ in the upper troposphere. In this study, since we focus on the tropical region where the lapse rate variation is small, these parameters are assumed to be only a function of channel frequency and cloud top height. For small IWP values, $T_{\text {cir }} \simeq T_{\text {ciro }}(-\mathrm{IWP} / H)$, which is a linear relationship as described by Wu and Jiang (2004) for Aura MLS. As also suggested by Wu and Jiang (2004), $H$ could be a function of cloud profile shape and the ice-to-water mixing ratio inside clouds, but these dependencies have secondary effects on the $T_{\text {cir }}-$ IWP relationship.

To derive the empirical $T_{\text {cir }}$-IWP relationship, we first sort all collocated measurements, CloudSat IWP (averaged onto MHS footprints) and MHS $T_{\text {cir }}$ at near-nadir views (scan angle $\left.\in\left[-5^{\circ}, 5^{\circ}\right]\right)$, to generate a joint PDF separately for each MHS channel. As shown in Fig. 3, the $T_{\text {cir }}$-IWP relationships are scattered with the PDF peaks in good agreement with Eq. (2). We then fit the 2-D PDF to obtain $T_{\text {ciro }}$ and $H$ parameters in Eq. (2), which is the solid curve in Fig. 3. The fitting is carried out as follows: (1) to determine $T_{\text {cir0 }}$ from the coldest $T_{\text {cir }}$. We search all 2010 MHS nadir data and the coldest $T_{\text {cir }}$ as $T_{\text {cir0 }}$ for each channel. (2) We then compute $H$ in Eq. (2) with the ordinary least squares method by fitting the $T_{\text {cir }}$ and IWP values at peak 2-D PDF (black dots in Fig. 3) using the $T_{\text {cir0 }}$ derived from step 1.

The fitted curves represent bulk characteristics of the joint PDF. Compared to a linear fit, the residual variances de-

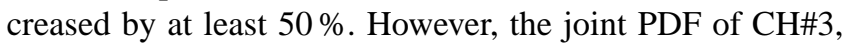
showing a steeper relationship for $T_{\mathrm{cir}}$ and IWP at colder $T_{\text {cir }}$ values, is not represented well by Eq. (2). Moreover, $T_{\text {cir }}$ PDF becomes flat at small IWP values (IWP $<0.5 \mathrm{~kg} \mathrm{~m}^{-2}$ ), indicating the lower limit of $T_{\text {cir }}$ sensitivity to IWP. The spread of 2-D PDF reflects both natural variability and collocation error of the $T_{\text {cir }}$-IWP relationship. One of the cloud variabilities that affect the $T_{\text {cir }}$-IWP relationship is the cloud top height $\left(h_{\mathrm{t}}\right)$.

To examine the dependency of $H$ on $h_{\mathrm{t}}$, we further sort the collocated measurements into three height groups using the mean $h_{\mathrm{t}}$ (defined as the highest altitude at which IWC reaches $10 \mathrm{mg} \mathrm{m}^{-2}$ ) computed from CloudSat cloud profiles: $9.5<h_{\mathrm{t}}<10.5 \mathrm{~km}, 11.5<h_{\mathrm{t}}<12.5 \mathrm{~km}$ and $13.5<h_{\mathrm{t}}<14.5 \mathrm{~km}$, each group separated by $1 \mathrm{~km}$ to avoid overlapping of the regression lines. These three height groups account for about $48 \%$ of all near-nadir collocated measurements. We then apply the same fitting procedure to obtain $T_{\text {ciro }}$ and $H$ for each height group as in Eq. (2) (solid thick lines in Fig. 4). For the three height groups, a cloud bottom height $\left(h_{\mathrm{b}}\right)$ is calculated to be within $7.5 \pm 1.6 \mathrm{~km}$, $8.5 \pm 2.5 \mathrm{~km}$ and $7.4 \pm 2.5 \mathrm{~km}$, respectively, so that the collection represents tall and thick deep convective clouds in the tropics. The measurements with $h_{\mathrm{t}}$ below $8.5 \mathrm{~km}$ and above 

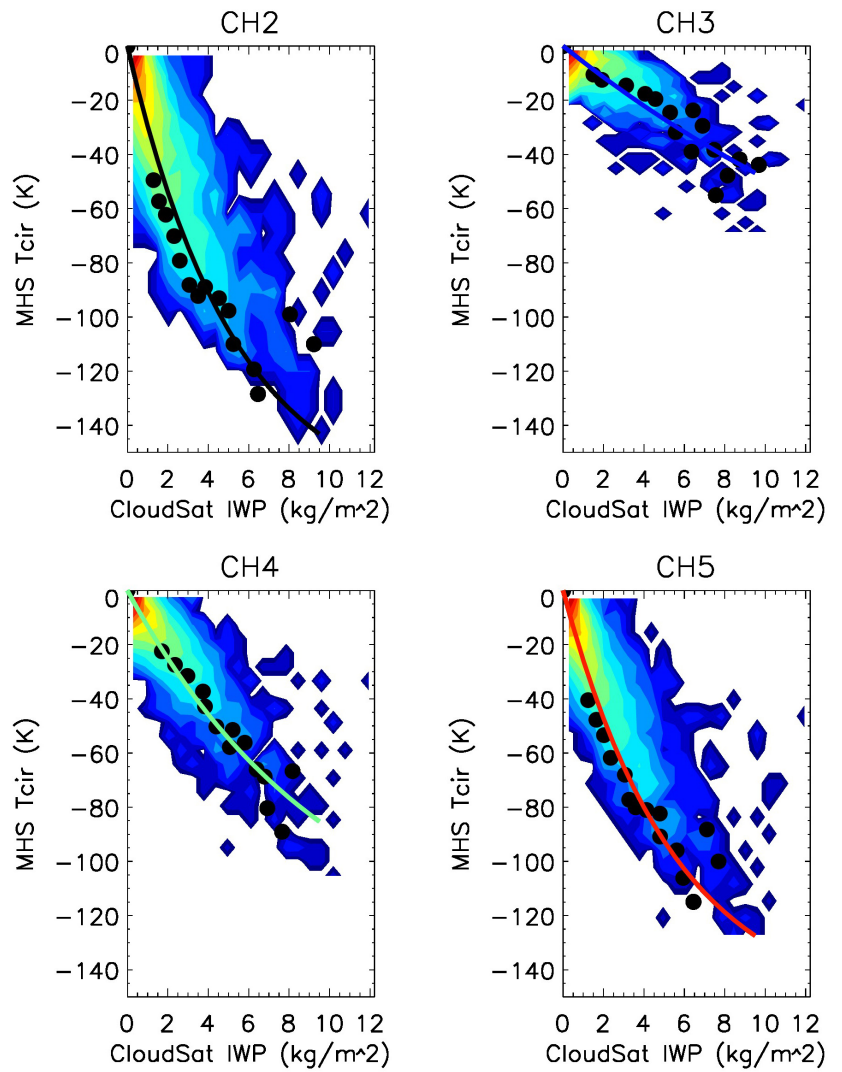

Figure 3. Contours of 2-D PDFs (normalized by the maximum value of the histogram) of collocated CloudSat IWP (abscissa, averaged onto MHS footprints) and MHS $T_{\text {cir }}$ (ordinate) for $\mathrm{CH \# 2-}$ $\mathrm{CH \# 5}$ at near-nadir views (scan angle $\in\left[-5^{\circ}, 5^{\circ}\right]$ ). Black dots locate the peak of the 2-D PDFs, and the thick solid lines are regression curves using Eq. (2).

$15.5 \mathrm{~km}$ are too few to obtain a statistically robust $T_{\text {cir }}$-IWP relationship.

Fig. 4 shows that $T_{\text {cir }}$ is more sensitive to IWP for clouds

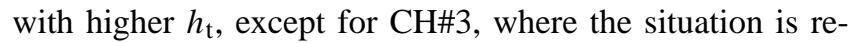
versed. This variation in $T_{\text {cir }}$ sensitivity is expected, according to the sensitivity expression from a conceptual cloud scattering model (Eq. 6.3 in Wu and Jiang, 2004)

$\frac{T_{\text {cir }}}{\tau_{\text {ceff }}} \approx T_{\text {scat }}-T_{\mathrm{AB}}$

where $\tau_{\text {ceff }}$ is the cloud effective optical depth that is positively correlated with IWP, $T_{\text {scat }}$ is the cloud scattering radiance from a convolution of the upwelling and downwelling radiation, and $T_{\mathrm{AB}}$ is the background clear-sky radiance beneath the cloud. For a given channel, $T_{\mathrm{AB}}$ remains the same no matter how thick or thin the ice cloud is. For thick, high $h_{\mathrm{t}}$ clouds, $T_{\text {scat }}$ is colder due to more contributions from higher altitudes, resulting in a larger $T_{\text {cir }}$ sensitivity to IWP. The CRM used by Wu and Jiang (2004) for Aura MLS predicts a similar but weaker $h_{\mathrm{t}}$ dependence, due to the fact that MLS is
Table 1. Look-up table for the parameters of the joint $I W P-h_{\mathrm{t}}$ retrieval.

\begin{tabular}{rrrrr}
\hline & $\begin{array}{r}T_{\text {cir0 }} \\
{[\mathrm{K}]}\end{array}$ & $\begin{array}{r}c_{0} \\
{\left[\mathrm{~kg} \mathrm{~m}^{-2}\right]}\end{array}$ & $\begin{array}{r}c_{1} \\
{\left[\mathrm{~g} \mathrm{~m}^{-3}\right]}\end{array}$ & $\begin{array}{r}c_{2} \\
{\left[\mathrm{mg} \mathrm{m}^{-4}\right]}\end{array}$ \\
\hline $\mathrm{CH \# 2}$ & -172 & 21.45 & -1.9875 & 0.5625 \\
$\mathrm{CH \# 4}$ & -140 & 17.021 & -0.4078 & 0 \\
$\mathrm{CH \# 5}$ & -155 & 29.6511 & -2.26214 & 0.038156 \\
\hline
\end{tabular}

a limb sounder that observes the cloud side in its LOS rather than the cloud top seen from a nadir sensor.

Since we do not have an accurate model of $H$ dependence on $h_{\mathrm{t}}$, a quadratic function is assumed to interpolate and extrapolate $H\left(h_{\mathrm{t}}\right)$ to the cases beyond the values at the observed $h_{\mathrm{t}}$, i.e., $h_{\mathrm{t}}=10,12$ and $14 \mathrm{~km}$. The coefficients in Eq. (4) are solved from the observed $H$ values for three $h_{\mathrm{t}}$ groups with the mean values at 10,12 and $14 \mathrm{~km}$. Including $T_{\text {ciro }}$, all the parameters of the empirically derived $T_{\text {cir }}-$ IWP relationships for $\mathrm{CH} 2, \mathrm{CH} 4$ and $\mathrm{CH} \# 5$ are listed in the look-up table 1.

$H=c_{0}+c_{1} h_{\mathrm{t}}+c_{2} h_{\mathrm{t}}^{2}$

The $h_{\mathrm{t}}$-dependent $H$ parameter allows a simultaneous retrieval of $h_{\mathrm{t}}$ and IWP. By including or constraining $h_{\mathrm{t}}$ in the retrieval, it improves the IWP retrieval. Other approaches, e.g., using IR channels from the $\mathrm{CO}_{2}$ slicing method (Kahn et al., 2008) may be used in the future to constrain $h_{\mathrm{t}}$ in the IWP retrieval. As seen in Fig. 4, the error bar for each of the three cloud groups is smaller than one without the height separation. Relaxing the collocation requirements would increase the number of measurements for statistics, but we find that it does not reduce the error bar of the derived $T_{\text {cir }}-$ IWP relationship.

To complete the empirical model for the $T_{\text {cir }}-$ IWP relationship, we need to extend the parameters listed in Table 1 from the near-nadir case to all MHS scan angles. For offnadir views, to account for longer off-nadir LOS $(\zeta$ is the local zenith angle), the $T_{\text {cir }_{\text {off-nadir }}}$ needs to be multiplied by $\cos \zeta$ to achieve an equivalent nadir $T_{\text {cir }}$, assuming planeparallel cloud layers. This is not a bad assumption in the case where clouds are not opaque. For opaque clouds, inhomogeneity plays a more important role in relating off-nadir and nadir views. In other words, the scan-angle correction for $T_{\text {cir }}$ is a function of $T_{\text {cir }}$ as well. Thus, we develop an empirical solution for this correction, which is given in Appendix A.

\subsection{Joint retrieval of IWP and $h_{\mathrm{t}}$}

The IWP and $h_{\mathrm{t}}$ are retrieved using the sequential estimation approach as described in Rodgers (2000) and Livesey et al. (2006). Equation (5) in Livesey et al. (2006) is quoted as 

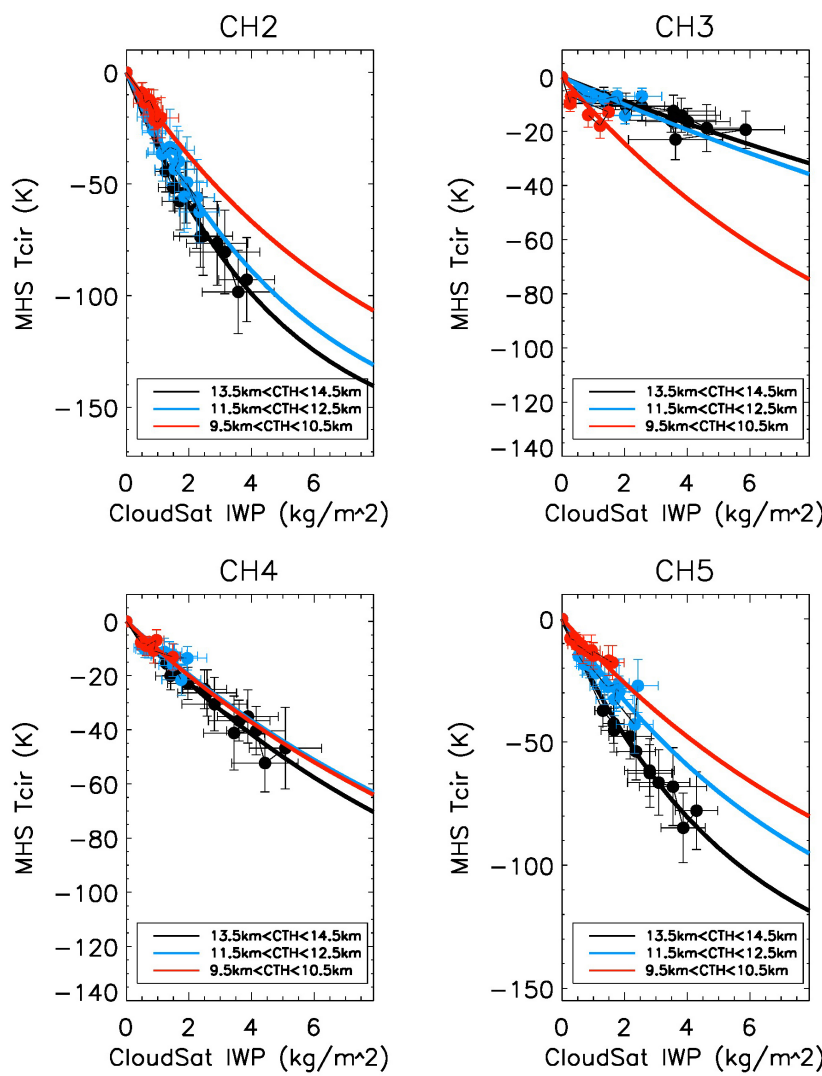

Figure 4. PDF peaks (uncertainties given as error bars) and the corresponding regression lines based on Eqs. (2) and (4) for clouds with $h_{\mathrm{t}}$ between 13.5 and $14.5 \mathrm{~km}$ (black), 11.5 and $12.5 \mathrm{~km}$ (blue) and 9.5 and $10.5 \mathrm{~km}$ (red) for $\mathrm{CH \# 2-CH \# 5} \mathrm{at} \mathrm{near-nadir} \mathrm{views.}$

Eq. (5) below:

$\left.x^{(q+1)}=x^{(q)}+\mathbf{S}_{x}\left[\mathbf{K}^{T} \mathbf{S}_{y}^{-1}\left(y-T_{\text {cir }}^{(q)}\right)\right)+\mathbf{S}_{a}^{-1}\left(a-x^{(q)}\right)\right]$

(q) annotates the $q$ th step of iteration. In our case, $x=$ [IWP,$\left.h_{\mathrm{t}}\right]$ is the retrieved result, $y=\left[T_{\mathrm{Cir}_{2}}, T_{\mathrm{Cir}_{4}}, T_{\mathrm{Cir}_{5}}\right]$ is the observation, and $T_{\text {cir }}^{(q)}$ can be calculated using Eq. (2) and $x^{(q)} . \mathbf{K}$ is the Jacobian matrix, which is defined as

$\mathbf{K}=\left[\begin{array}{c}\frac{\partial T_{\text {cir }}}{\partial \mathrm{IWP}} \\ \frac{\partial T_{\mathrm{cir}}}{\partial h_{\mathrm{t}}}\end{array}\right]=\left[\begin{array}{c}\frac{T_{\mathrm{cir} 0}}{H} \cdot e^{-\mathrm{IWP} / H} \\ -\frac{T_{\mathrm{cir} 0} \cdot \mathrm{IWP}}{H^{2}} \cdot e^{-\mathrm{IWP} / H} \cdot\left(c_{1}+2 c_{2} h_{\mathrm{t}}\right)\end{array}\right]$.

Plotted in Fig. 5 are the analytical solutions of $\mathbf{K}$ using the coefficients listed in Table 1 and Eq. (6). $\partial T_{\text {cir }} / \partial I W P$ (left column of Fig. 5) monotonically increases with IWP for all three channels without any singularity point or multiple solutions. However, $\partial T_{\text {cir }} / \partial h_{\mathrm{t}}$ (right column of Fig. 5) has a singularity point at $h_{\mathrm{t}}=18 \mathrm{~km}$ for $\mathrm{CH} 2$, where multiple solutions exist. For $\mathrm{CH} \# 5$, multiple solutions can also occur for $h_{\mathrm{t}}$. If we define the bottom of the $\partial T_{\text {cir }} / \partial h_{\mathrm{t}}$ curve as $h_{t_{\text {critical }}}$, then the smaller the IWP is, the higher $h_{t_{\text {critical }}}$ is. For instance, $h_{\text {tcritical }}$ at IWP $=3.0 \mathrm{~kg} \mathrm{~m}^{-2}$ is $18 \mathrm{~km}$, meaning that if the cloud has $h_{\mathrm{t}}>18 \mathrm{~km}$ and IWP $=3.0 \mathrm{~kg} \mathrm{~m}^{-2}$, the
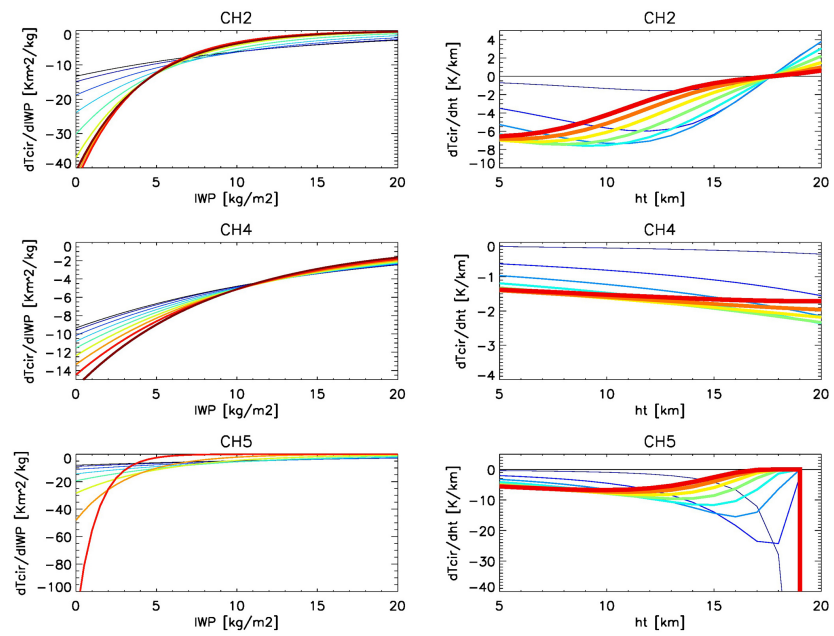

Figure 5. Analytical solutions of the two components of the Jacobian matrix K: $\partial T_{\text {cir }} / \partial$ IWP with fixed $h_{\mathrm{t}}$ (left) and $\partial T_{\text {cir }} / \partial h_{\mathrm{t}}$ with fixed IWP (right). For the left column, the fixed $h_{\mathrm{t}}$ value increases from 6 (thin, blue) to $20 \mathrm{~km}$ (thick, red) with an interval of $2 \mathrm{~km}$. For the right column, the fixed IWP value increases from 0.5 (thin, blue) to $18 \mathrm{~kg} \mathrm{~m}^{-2}$ (thick, red) with an interval of $2.5 \mathrm{~kg} \mathrm{~m}^{-2}$.

retrieved $h_{\mathrm{t}}$ has a possibility of being underestimated. The $\mathbf{K}$ matrix responses at $\mathrm{CH \# 2}$ and $\mathrm{CH \# 5}$ suggest that the $h_{\mathrm{t}}$ retrieval could significantly underestimate the truth when cloud top is above $18 \mathrm{~km}$, especially for thick, dense clouds.

$a=\left[\mathrm{IWP}_{0}, h_{t_{0}}\right]$ is the a priori (initial guess) of $x$. In practice, if $T_{\text {cir }}$ from all three channels is less than $-5 \mathrm{~K}$, there is a strong possibility of ice cloud presence, and $h_{\mathrm{t}_{0}}$ is set to $5 \mathrm{~km}$ to speed up the convergence of the iteration. Otherwise, $h_{\mathrm{t}_{0}}$ is set to $0 \mathrm{~km}$ instead. The initial guess of $\mathrm{IWP}_{0}$ is always set to 0 . Once the iteration begins, $a$ is forced to equal to $x^{(q)}$ to avoid "artificial preference" of retrievals to the a priori. That is to say, the last term on the right-hand side of Eq. (5) can be eliminated. The total number of iteration steps is set to 20 regardless of whether the final results converge or not. Within each iteration, $\operatorname{IWP}^{(q)}$ is not allowed to exceed $25 \mathrm{~kg} \mathrm{~m}^{-2}$ or become negative, and the $h_{\mathrm{t}}^{(q)}$ value must be within the range of $[0,18] \mathrm{km}$. The lower bounds assure physically meaningful solutions. The upper bound of $h_{\mathrm{t}}$ is where $\mathrm{CH} \# 2$ and $\mathrm{CH} \# 5$ are problematic in retrieving a trustable $h_{\mathrm{t}}$ with the set of coefficients listed in Table 1. Therefore, the protection of the $h_{\mathrm{t}}$ solution again significantly under-evaluates the $h_{\mathrm{t}}$ for those high, dense clouds. Nevertheless, IWP rarely exceeds $25 \mathrm{~kg} \mathrm{~m}^{-2}$, and the monochromaticity of $K$ with respect to IWP assures the robustness of IWP retrievals.

$S_{y}, S_{a}$ and $S_{x}$ are the matrices describing the error covariances associated with the measurements, the a priori, and the final retrieval results, respectively. $S_{y}=[5,5,5]^{2} \mathrm{~K}^{2}$ as the measurement error is estimated to be $5 \mathrm{~K}$ (Sect. 2.1.3). $S_{a}$ associates with the CloudSat IWC retrieval error, which is estimated to be less than $\sim 50 \%$ (Austin et al., 2009). In practice however, $S_{a}$ defines the step allowed to jump in each 
iteration, which needs to be small in very nonlinear cases where multiple solutions exist and large steps could result in an unstable retrieval. Since the retrieval function is monotonic for all channels, a large step $S_{a}=\left[6 \mathrm{~kg} \mathrm{~m}^{-2}, 6 \mathrm{~km}\right]^{2}$ is chosen, as in the so-called Newtonian iteration, to accelerate the retrieval convergence. Once $S_{y}$ and $S_{a}$ are fixed, $S_{x}$ at each iteration step can then be calculated from Eq. (5), which is shown as Eq. (7):

$\mathbf{S}_{x}=\left[\mathbf{K}^{T} \mathbf{S}_{y}^{-1} \mathbf{K}+\mathbf{S}_{a}^{-1}\right]^{-1}$.

The retrieval is not carried out if $T_{\text {cir }}$ at all three channels is greater than $5 \mathrm{~K}$, a strong indication of a clear sky. In that case, we directly assign a clear-sky flag to the scene. $\mathrm{CH \# 2}$ radiance is excluded for retrievals over arid areas because of its contamination by surface signals. This is realized by checking land pixels with $T_{\text {cir }}<-5 \mathrm{~K}$ for all three channels (i.e., ice cloud likely). As long as this criterion is not satisfied, only $\mathrm{CH} \# 4$ and $\mathrm{CH} \# 5$ are used for the retrieval over land, whereas $\mathrm{CH \# 2}$ is always used over oceans. After retrieval, the IWP value that has the standard deviation $\left(\sqrt{S_{x}[1]}\right)$ greater than or equal to itself is flagged as "bad quality"; so is $h_{\mathrm{t}}$. The rest is flagged as "good quality".

\section{Assessment of IWP and $h_{\mathrm{t}}$ retrievals}

Comparisons of IWP retrievals have been challenging and sometimes even confusing because not all sensors measure the same portion of pIWP. Different cloud bottom and top heights can affect the cloud ice sensitivity and retrieval results. For MHS, the channel penetration depth varies with water vapor loading above cloud and with liquid water amount inside clouds if it is a mixed-phase case. In addition, cloud inhomogeneity along LOS introduces more uncertainties to this comparison task. Active microwave sensors such as CloudSat do not have the penetration depth issue for most clouds. In this study we treat its IWP as the truth when comparing it with the measurements from passive sensors (e.g., $\mathrm{Wu}$ et al., 2009). Since the retrieval algorithm developed here is constrained by CloudSat IWP, the IWP retrieved from MHS is expected to be statistically close to CloudSat cloud ice. In other words, MHS penetration depth is "extrapolated" to reveal the total column IWP using this algorithm. In this section we compare the PDFs of monthly IWP as well as the mean IWP maps for MHS and CloudSat data.

\subsection{Comparison of IWP PDFs}

Normalized PDF has been used to compare the cloud ice products and sensitivities from multiple sensors (Su et al., 2009; Wu et al., 2009). The fundamental assumption of this approach is that cloud ice should have the same probability distribution if both sensors are measuring the same ensemble of clouds (e.g., in similar latitude regions and local time). Unlike the apple-to-apple comparison, vast data can be digested in one PDF plot that reveals ample information. The

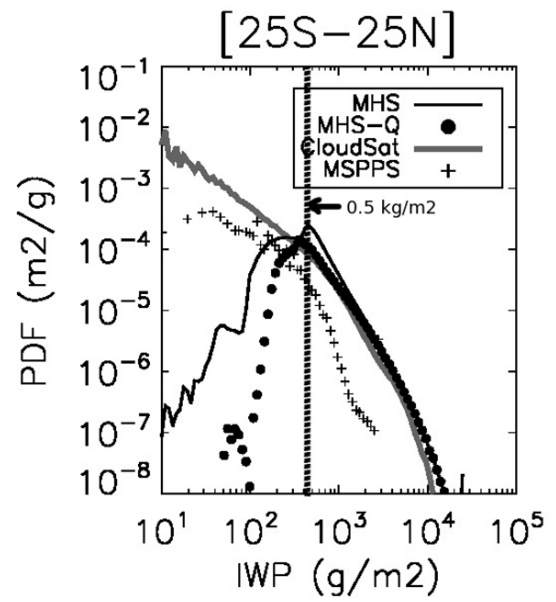

Figure 6. PDFs of CloudSat IWP (grey thick line; smoothed over 15 CloudSat footprints and integrated between 5 and $19 \mathrm{~km}$ ), all retrieved MHS IWP (black solid line; from all views), retrieved MHS IWP that is quality controlled (black dots), and MSPPS IWP (black crosses; from all views; from NOAA-18 only) for August 2010 in the tropics.

basic philosophy of this approach is that the variable of interest should have the same probability of observing a certain value with what nature shows within the product's visibility range. Therefore, if the probability is smaller (greater) than that from the truth, the variable (e.g., cloud occurring frequency) is under-(over-)estimated. The PDF comparison also overcomes the instrument geometry difference, as explained in $\mathrm{Wu}$ et al. (2009).

As expected for the CloudSat-constrained retrieval, MHS IWP PDF agrees well with CloudSat, as shown by the grey and black lines in Fig. 6. The decreasing probability with IWP reflects the natural variability of cloud ice. CloudSat IWPs here are 15-FOV averaged values in order to mimic the MHS footprint diameter, which is slightly steeper than the original (non-averaged) PDF, or a higher (lower) possibility at smaller (larger) IWP. The averaging effect $(<10 \%$ in PDF values) is negligible compared to the differences among various data sets/retrievals. When all good and bad retrievals from the 90 MHS views are included, the PDF (solid black line) in Fig. 6 rises more sharply at small IWPs $\left(\sim 500 \mathrm{~g} \mathrm{~m}^{-2}\right)$ due to the arbitrary retrieval suppression for negative IWP values and false detection of clear-sky scenes. The dropping PDF at IWP $<500 \mathrm{~g} \mathrm{~m}^{-2}$ is mostly noise. When the quality flag is applied to exclude bad retrievals, the PDF (dots) agrees better with CloudSat at IWP $>300 \mathrm{~g} \mathrm{~m}^{-2}$. At large values $\left(>8 \times 10^{3} \mathrm{~g} \mathrm{~m}^{-2}\right)$, our algorithm tends to slightly over-estimate IWP when compared to CloudSat.

The PDF of NOAA operational MSPPS data (crosses in Fig. 6) is lower than CloudSat at all IWP values. At large IWP values (IWP $>10^{3} \mathrm{~g} \mathrm{~m}^{-2}$ ), it differs by 10 times or more, indicating that the operational product significantly underestimates cloud ice, compared to CloudSat. This low 

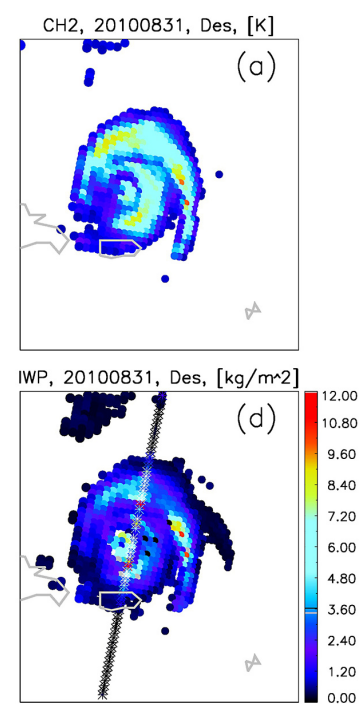
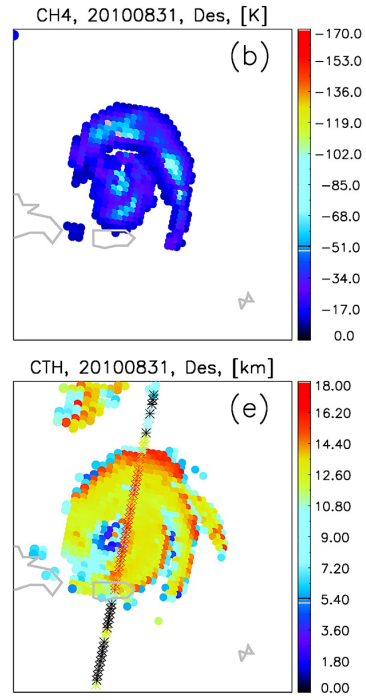

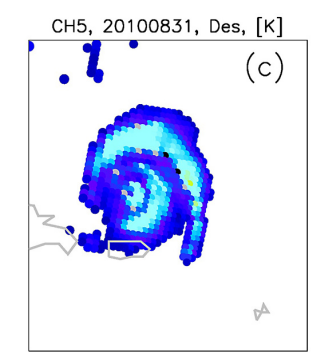

MCPPS IWP, 20100831, Des, [kg/m^2]

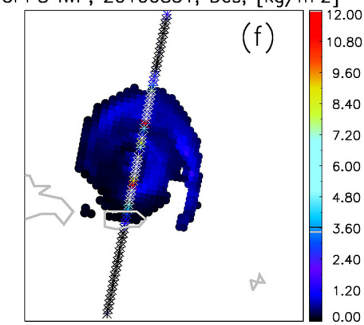

Figure 7. $T_{\text {cir }}$ at $\mathrm{CH \# 2} \mathrm{(a),} \mathrm{CH \# 4}(\mathbf{b})$ and $\mathrm{CH \# 5}(\mathbf{c})$ and retrieved NOAA-18 MHS IWP (d), $h_{\mathrm{t}}(\mathbf{e})$ and MSPPS IWP (f) for Hurricane Earl at 01:54 LST on 31 August 2010 (Cuba is the island to the left of the plot). The IWP $\left(h_{\mathrm{t}}\right)$ calculated from the collocated and coincident CloudSat overpasses (averaged onto MHS footprints) are marked by color crosses that share the same color bars with MHS. Note that the blank in the IWP map means that the IWP retrieval is not performed or has failed because it is below the sensitivity level of this algorithm, while CloudSat overpasses show a zero IWP value in most places away from the hurricane.

bias was also reported in other studies (e.g., Waliser et al., 2009; Eliasson et al., 2011).

The quality of our cloud ice retrieval is demonstrated clearly in a scene over Hurricane Earl on 31 August 2010 (Fig. 7a-c). $T_{\text {cir }}$ in all three MHS channels captured the structure of Hurricane Earl very well, showing the eye, eye wall and spiral rain bands. $\mathrm{CH} \# 2$ radiances, penetrating the deepest, reveal more ice cloud structures than other channels. The retrieved IWP from our algorithm (Fig. 7d) retains most of the fine structures in $\mathrm{CH \# 2}$ and also shows a hint of an additional two outer arms. Although the values of these arms are below the noise level, they are probably real because they are also present in the geostationary satellite IR image (not shown). The IWP from CloudSat overpasses (colored crosses) have slightly larger values than MHS, whereas MSPPS operational IWP (Fig. 7f) are significantly smaller than CloudSat and our retrievals. This hurricane case also highlights the value of MHS IWP in studying the 2-D atmospheric dynamics and cloud structures that are not captured by the CloudSat curtain sampling. Using the CloudSatconstrained IWP measurements, we can obtain good spatial and temporal coverage from the MHS/AMSU-B sensors onboard all operational satellites.

Retrieved $h_{\mathrm{t}}$ (Fig. 7e) also agree reasonably well with CloudSat, especially at the hurricane periphery and the eye wall, but are lower by $\sim 4 \mathrm{~km}$ over the hurricane deck $(13 \mathrm{~km}$ versus $>18 \mathrm{~km}$ ). This is probably due to the fact that the cloud top at the deck is dominantly higher than that at the hurricane periphery, i.e., higher than $18 \mathrm{~km}$. They hence exceed the upper limit of the reliable $h_{\mathrm{t}}$ retrieval range from our algorithm. Pixel-by-pixel comparisons are done for some other cases that have CloudSat cloud tops lower than $18 \mathrm{~km}$, and the $h_{\mathrm{t}}$ retrieval seems quite promising (not shown). Nevertheless, the $h_{\mathrm{t}}$ retrieval here is mainly to improve IWP retrieval, rather than the purpose of scientific study.

As the first CloudSat-calibrated column-wise IWP measurement that has excellent spatial coverage, the MHS IWP retains numerous potential usages for model input, for validation of other instrument measurements and for modelobservation comparisons in the future.

\subsection{Geographic distribution of IWP}

Monthly mean IWP maps show good correlation between MHS and CloudSat cloud ice for August 2010 (Fig. 8), where the correlation is 0.81 in the tropics. Sampling error is evident in these maps. With a relatively coarse grid box $\left(5^{\circ} \times 5^{\circ}\right)$, the CloudSat monthly maps (Fig. 8a, c) are spotty due to a lack of swath coverage. This sampling is also aligned to the westward-traveling fast cloud systems, leading to cloud ice spikes (e.g., eastern Pacific) and scatters (e.g., Amazon rainforest) on the CloudSat maps (e.g., Amiridis et al., 2013). The sampling bias is largely mitigated by the 90 -FOV MHS swath, maps of which look much smoother instead (Fig. 8b, d) because it overpasses one grid box 6 times as often as CloudSat on average. If the footprint size is taken into consideration, MHS could pass every corner of each $5^{\circ} \times 5^{\circ}$ grid box in the tropics by as many as 42 times within a month, while CloudSat covers only $4 \%$ of the area in the tropics. The major features between the two data sets agree well, especially in deep convective regions where IWPs are large. The 


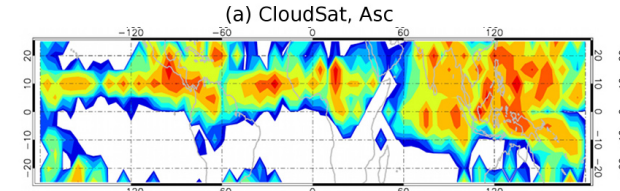

(c) CloudSat, Des

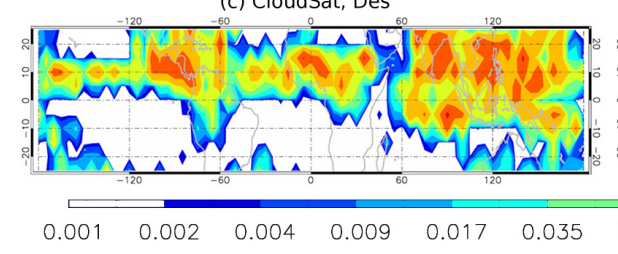

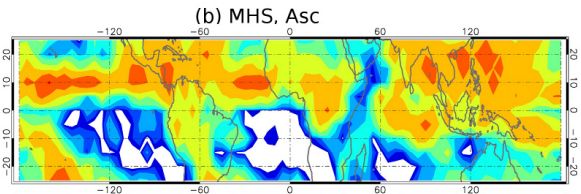

(d) MHS, Des

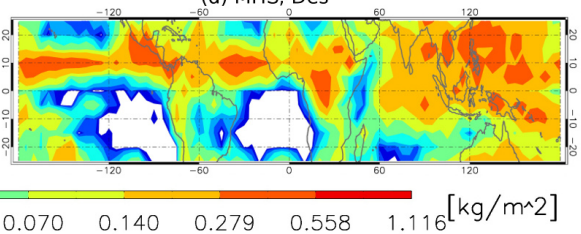

Figure 8. Monthly averaged IWP from CloudSat and MHS ascending (a, b) and descending (c, d) orbits during August 2010. MHS IWP is averaged over all views. Data are sampled to $5^{\circ} \times 5^{\circ}$ grid boxes.

day-night differences in ice cloud thickness seen in CloudSat are also evident in the MHS maps, e.g., in central America and central Africa.

Interestingly, in the scatter plot of MHS and CloudSat IWPs at a logarithm scale, the correlation is not along the 1:1 line, showing a higher bias in MHS at smaller IWP values. The overall regression yields IWP $_{\text {CloudSat }}=(0.83 \pm$ 0.017)IWP $\mathrm{IHS}_{\mathrm{MH}}-14.7\left[\mathrm{~g} \mathrm{~m}^{-2}\right.$ ], shown as the blue dots in Fig. 9b. The $-14.7 \mathrm{~g} \mathrm{~m}^{-2}$ offset partly comes from elevated topographies, e.g., the Andes, and from deserts, e.g., central Australia. The bias is slightly worse during night (MHS descending orbit) than during the day (MHS ascending orbit). If $\mathrm{CH} 2$ is included for the MHS IWP retrievals over land, the high bias would increase over Australia, which may suggest a warm bias in MERRA surface temperature or aproblem with surface emmisivity in that region during nighttime

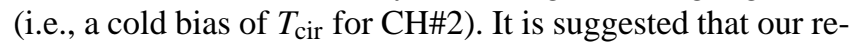
trieval algorithm has some limitations over complicated surface conditions, which will be discussed in the next section. Part of the $-14.7 \mathrm{~g} \mathrm{~m}^{-2}$ offset is caused by the fact that MHS tends to slightly over-estimate IWP with respect to CloudSat, especially for thick and dense clouds. Besides, CloudSat probably misses some convections due to its sampling bias, for instance, over the Amazon rainforest and the maritime continent. Visual comparison between MODIS ice cloud optical depth (Fig. 7 of Meyer et al., 2007) and MHS IWP shows better agreement in these regions. It is worth mentioning that collocated MHS-CloudSat retrieved IWP showed the same feature. However, by subtracting the square root of the error $\left(S_{x}\right)$, MHS IWP does not have such a positive bias (not shown). Therefore, despite the fact that MHS is still noisy below $0.5 \mathrm{~kg} \mathrm{~m}^{-2}$ at a single retrieval, the error estimation is very reasonable, and helps in filtering out the bad retrievals.

\subsection{Limitations of the algorithm}

The empirical forward model ( $T_{\text {cir }}$-IWP relationships) and retrieval algorithm presented in this paper are designed for tropical regions and have difficulties in retrieving IWP over
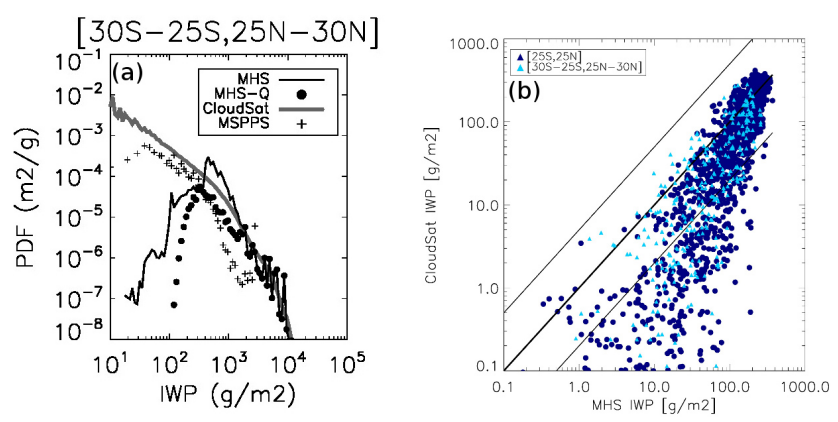

Figure 9. (a) is the same as Fig. 6, except from different latitude bins (see sub-titles for the latitude range). (b) is the scatter plot of MHS (abscissa) and CloudSat (ordinate) gridded monthly mean IWP for latitude bins between $\left[25^{\circ} \mathrm{S}, 25^{\circ} \mathrm{N}\right]$ (blue filled dots), $\left[25^{\circ}\right.$, $\left.30^{\circ}\right] \mathrm{N}$, and $\mathrm{S}$ (light blue triangle). The map grid size is $5^{\circ} \times 5^{\circ}$, and data are then smoothed by a two-point window along latitude and longitude before making the scatter plot. The black thick (thin) line marks the $1: 1(1: 5$ and $5: 1)$ ratio.

elevated topography and desert. In the cases of mixed-phase clouds or excessive water vapor abundance above cloud tops, the retrieval error for IWP might increase. The major causes of the biases over land are likely the CRTM surface emissivity error in modeling the surface radiation, or surface temperature error in the mountain and desert regions in the MERRA data. Since $\mathrm{CH \# 2}$ radiance contains surface signals ( $\mathrm{CH \# 5}$ sees arid and snow surfaces as well), uncertainties in surface temperature and emissivity will induce $T_{\text {cir }}$ biases. As a matter of fact, we do see a systematic warm bias of $2 \mathrm{~K}$ in $\mathrm{CH} \# 2$ $T_{\text {cir }}$ (Appendix B), which could be due to the instrument calibration error or $T_{\mathrm{ccr}}$ model error. Moreover, the PDF of $T_{\mathrm{ccr}}$ for $\mathrm{CH \# 2} \mathrm{(Fig.} \mathrm{1b)} \mathrm{extends} \mathrm{to} \mathrm{a} \mathrm{temperature} \mathrm{as} \mathrm{low} \mathrm{as} 220 \mathrm{~K}$, which is strong evidence of contamination from clouds or cold surfaces (i.e., ice pack on mountains can also cause this low $T_{\mathrm{B}}$ ). With the development of a neural network approach, the initial guess of $T_{\mathrm{ccr}}$ could be used to improve the cloud ice retrieval over complicated surface conditions (Chen and Staelin, 2003). 

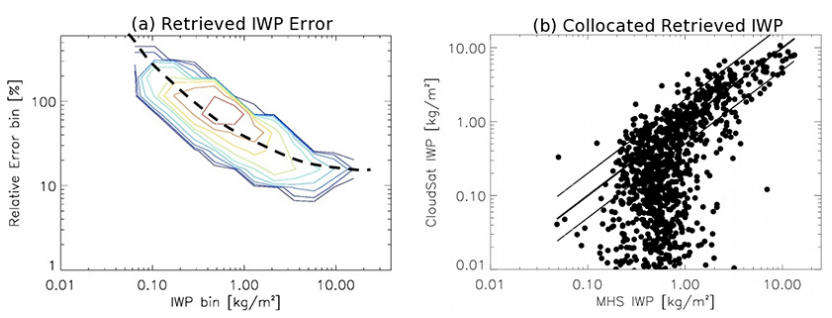

Figure 10. (a) PDF of relative error $\left(\sqrt{S_{\text {IWP }}} / \mathrm{IWP}, \%\right)$ of onemonth retrieved IWP between $30^{\circ} \mathrm{S}$ and $30^{\circ} \mathrm{N}$. Contours are in $\log$ scale. The peak of the PDF is roughly marked by hand to represent an exponential decrease (thick dashed line). (b) Collocated CloudSat-MHS IWP retrievals for July 2010 within the same latitude band. The thick solid line is the $1: 1$ line, and the other two thin solid lines mark the $1: 2$ and $2: 1$ ratios, respectively.

The parameters in Table 1 assume that the atmospheric temperature lapse rate $\gamma$ is constant in the tropics. As predicted by $\mathrm{Wu}$ and Jiang (2004) using CRM, the $T_{\mathrm{cir}}$-IWP relationship is also a function of $\gamma$ (Fig. 6.10 therein). Evaluating the PDFs of retrieved IWP outside the tropics, we find that the PDF of extratropical IWP starts to oscillate at its large-value tail (Fig. 9a) compared with that in the tropics (Fig. 6). The quality-controlled PDF in this case is still comparable with CloudSat PDF though for this bin assuming a $100 \%$ tolerance level of the PDF difference. Hence, our algorithm is expected to perform well within latitudes of $30^{\circ} \mathrm{N}, \mathrm{S}$, but degrades in the extratropics. The mean vertical temperature profiles are also similar to those in the tropics up to $30^{\circ}$ in latitude (Fig. 6.9 in Wu and Jiang, 2004). At middle to high latitudes beyond $30^{\circ}$, the quality-controlled PDFs are too low or even alter its shape, and the retrieved MHS IWP merely correlate with CloudSat IWP (not shown). In future algorithm development, $\gamma$ should be treated as an independent variable, such that the algorithm can be applied for IWP retrievals at higher latitudes.

Liquid clouds occur frequently below $5 \mathrm{~km}$, where temperature is usually greater than $0^{\circ} \mathrm{C}$ (Riedi et al., 2001), which may have little impact on $\mathrm{CH \#} 4$ but can significantly affect $\mathrm{CH} \# 2$ and $\mathrm{CH} \# 5 T_{\text {cir. }}$. For deep convective clouds, liquid droplets can be lifted to a much higher altitude. The mixing of liquid droplets into ice cloud enhances the cloud emission contribution at microwave frequencies and hence decreases the $T_{\text {cir }}$ sensitivity to IWP. Wu and Jiang (2004) showed that this impact could be as large as 30-50\% in a strong mixedphase case, which alters the relationship in Eq. (2) with different parameters. Therefore, mixed-phase clouds can contribute significantly to the spread of the 2-D PDF shown in Figs. 3 and 4.

Water vapor above and inside cloud plays a screening role in reducing the sensitivity to IWP, in a way similar to liquid droplets. Since $\mathrm{CH \#} 4$ and $\mathrm{CH \# 5}$ are water vapor channels, they are sensitive to the water vapor abundance above and inside ice clouds. As a result, $T_{\text {ccr }}$ calculation could be biased if MERRA water vapor is too dry or too wet above clouds. The water vapor impact was only evaluated using CRM with different water vapor profiles, assuming variability within the uncertainty of observed upper-troposphere water vapor. The water vapor impact is found to be small and negligible in these CRM simulations (less than $5 \%$ with doubling water vapor amount above clouds).

\subsection{Error analysis}

The retrieval error $\left(S_{x}\right)$ provides a direct estimate of the retrieval uncertainty. This uncertainty is completely independent of CloudSat IWP retrieval uncertainty. There are further sources of error, for example, the imperfect "coincident collocation", the uncertainty induced by limited collocation samples, cloud misclassifications, etc. The total error is a combination of the three. This section will be focused on delineating the error sources and quantifying them one by one.

The retrieval error $S_{x}$ is a dependent of the observational uncertainties from MHS $\left(S_{y}\right)$ and from the forward model (K matrix), represented by Eq. (7). For small IWP values (thin ice cloud), $S_{x}$ is dominated by $S_{y}$ (i.e., MHS instrument noise). Since $S_{y}$ is fixed at $5 \mathrm{~K}$ for all three channels, this algorithm loses its sensitivity for IWP values smaller than $0.5 \mathrm{~kg} \mathrm{~m}^{-2}$, which is evident in Figs. 9a and in $10 \mathrm{~b}$. For large IWP values (thick or precipitating ice cloud), $S_{x}$ is controlled by the uncertainty of the forward model. In the case when $T_{\text {cir }}$ saturates (i.e., smaller than $T_{\text {ciro }}$ in Table 1), the forward model uncertainty is infinite as the Jacobian curve of the $\mathbf{K}$ matrix with respect to IWP flattens out from $T_{\text {ciro }}$ onward. However, the $\mathbf{K}$ matrix is still very sensitive to IWP as long as $T_{\text {cir }}$ does not saturate, as shown in Fig. 5. Therefore, the induced error in $S_{x}$ from the forward model uncertainty is relatively small for large IWP values. This is confirmed by Fig. 10a, where the percentage range of retrieval error $\left(\sqrt{S_{\text {IWP }}} /\right.$ IWP $)$ decreases quickly from above $100 \%$ at small IWP values to as low as $20 \%$ at large IWP values (IWP $>1 \mathrm{~kg} \mathrm{~m}^{-2}$ ). Error is also reflected in the retrieval results, shown in one month's worth of collocated CloudSatMHS IWP retrievals in Fig. 10b. It is apparent that collocated retrievals are highly agreeable above $1 \mathrm{~kg} \mathrm{~m}^{-2}$, while MHS tends to overestimate thin cloud IWP.

Ice cloud misclassification is an unavoidable issue for any cloud retrieval technique. Cloud misclassification of this retrieval algorithm is partly induced by the beam-filling effect and mismatch of CloudSat and MHS footprints spatially and temporarily. It is hard to separate these two effects, as they are essentially the same. They are the major cause of the spread of the 2-D PDF and the uncertainty bars in Fig. 3 and Fig. 4, respectively. As a CloudSat footprint is much smaller than an MHS footprint, cloud inhomogeneity within an MHS FOV cannot be captured fully by averaging CloudSat footprints within the corresponding MHS FOV. Since we further relax the collocation and coincidence criteria, mismatches also occur. Both of them result in the cloud 
misclassification as described in the above paragraph. However, imperfect clear-sky background $\left(T_{\mathrm{ccr}}\right)$ can also cause a bias in $T_{\text {cir }}$, which can also induce cloud misclassification. One thing to notice is that the error of clear-sky radiance is internally included in $S_{y}$, as $S_{y}$ is directly estimated from $T_{\mathrm{B}}-T_{\mathrm{ccr}}$.

As truth is not given in our case, CloudSat is again used as the "truth" since the philosophy of this paper is to align MHS measurements with those of CloudSat. Two types of cloud misclassification exist: for one thing, MHS treats a footprint as an ice cloud being present, but collocated CloudSat measurements averaged onto the same MHS footprint do not report a positive IWP value. This is named "Type I" misclassification; for the other, which is on the contrary, it is called "Type II" misclassification. All collocated CloudSatMHS observations between $30^{\circ} \mathrm{S}$ and $30^{\circ} \mathrm{N}$ are compared through the entire year of 2010 to generate the statistics. For Type I misclassification, there is an $18.1 \%$ chance that MHS will detect an ice cloud but CloudSat will not, among which only $1 \%$ of the MHS retrieval reports an IWP greater than $0.5 \mathrm{~kg} \mathrm{~m}^{-2}$ (noise level). That means that using our technique, MHS nearly never misclassifies a clear-sky scene as cloudy sky and reports an IWP value beyond its noise level. Interestingly, the $18.1 \%$ misclassification cases do not prefer mountain or snowy regions like the Andes, albeit there is a slight enhancement of occurring frequency over the Australian desert. The latter is expected as discussed in Sect. 4.3. For Type II misclassification, there is a $45.8 \%$ chance that CloudSat will detect an ice cloud but MHS will not. Among these cases, $90.5 \%$ of the time CloudSat reports an IWP value less than $0.5 \mathrm{~kg} \mathrm{~m}^{-2}$. All in all, our technique shows a very strong confidence level for retrieved values greater than the detection threshold ( 2 and $4 \%$ misclassification rate for Type I and II, respectively), which means that our technique nearly never misses a thick ice cloud, even when the surface signal is complicated. On the other hand, our technique misses or gives large retrieval uncertainties of thin ice clouds like cirrus, which are not very important hydrologically (Fig. 8) but are important to the radiation budget.

It is difficult to justify the magnitude of other errors, which are blended in the error bars of the fitted curves in Fig. 4. The IWP error bar can be as large as $\pm 1 \mathrm{~kg} \mathrm{~m}^{-2}$ at IWP $=3 \mathrm{~kg} \mathrm{~m}^{-2}$ for $\mathrm{CH \# 4}$. Given the fact that the retrieval error should be smaller than any of the error bars generated from each individual channel, it is fairly reasonable to claim that the total retrieval error would be smaller than $100 \%$ when the retrieved IWP is beyond the detection threshold.

The overall retrieval error from this algorithm is quite small. As a matter of fact, it reflects the "precision" of the instrument and the forward model rather than the total error. One should always keep in mind that this is the error on top of the CloudSat IWP retrieval uncertainties. SPAREICE by Holl et al. (2014) showed a larger error in general, but their algorithm could quantitatively evaluate the contribution from each source, including CloudSat itself. The two algorithms are not directly comparable since we are under different metrics. Our algorithm meets the goal presented at the beginning, that to make cross-platform, cross-instrument consistent retrievals.

\section{Conclusions}

A fast empirical forward model built upon $T_{\text {cir- }}$-IWP relationships at MHS 157, 183.3 \pm 3 and $190.3 \mathrm{GHz}$ channels is developed and used to retrieve tropical cloud IWP from MHS radiance measurements. The $T_{\mathrm{cir}}$-IWP relationships at these channels are dependent on cloud top height $h_{\mathrm{t}}$ in the tropics (Fig. 4), and the algorithm for retrieving IWP and $h_{\mathrm{t}}$ simultaneously can improve the IWP accuracy. The IWP PDFs from MHS and CloudSat retrievals agree quite well, as expected for this constrained empirical forward model, over a wide dynamic range of cloud ice (IWP $=0.5-10 \mathrm{~kg} \mathrm{~m}^{-2}$, Fig. 6). The retrieval errors are also about the same magnitude (smaller than $100 \%$, Fig. 10). The empirical forward model is valid for clouds with $h_{\mathrm{t}}$ lower than $18 \mathrm{~km}$ and IWP greater than $0.5 \mathrm{~kg} \mathrm{~m}^{-2}$, but only in the tropics between $30^{\circ} \mathrm{S}$ and $30^{\circ} \mathrm{N}$ at present (Fig. 9). Beyond that latitude range, temperature lapse rate variations need to be taken into account to refine the $T_{\text {cir }}$-IWP relationship. In addition, the algorithm is not accurate for retrieving IWP over elevated and arid topography (Fig. 8).

Producing a CloudSat-consistent MHS IWP product has several direct benefits and important implications for studying clouds. Firstly, it helps to extend CloudSat cloud coverage with a wider swath width because frequent sampling from different operational satellites will allow frequent updates of fast-evolving weather phenomena such as hurricanes and frontal systems. The new data can be used to improve weather prediction (e.g., cloud diurnal cycle) and longterm regional climate monitoring (e.g., IWP trend). Secondly, our improved IWP retrieval method renders generally larger IWP values than the NOAA operational product (Figs. 6 and 7). The approach we implemented with highfrequency microwave channels improves cloud detection in scenes with high IWP. Compared with CloudSat monthly climatology as well as the single-orbit measurements, we found that our results are closer to the CloudSat integrated ice water path. Thirdly, we show that replacing the $89 \mathrm{GHz}$ channel with $183.3 \mathrm{GHz}$ channels for cloud ice retrieval reduces false detection of ice clouds and improves sensitivity to IWP as the higher-frequency channels are more sensitive to ice particle scattering. Lastly, the derived empirical $T_{\text {cir }}$-IWP relationships can be used to evaluate RTM simulations of cloudy-sky radiances, validate model assumptions, and improve model skills for data assimilation applications in the future (Fig. C1).

Although the empirical $T_{\text {cir }}$-IWP relationship developed here was from NOAA-18 MHS, it is applicable to the similar channels used by other AMSU-B/MHS instruments on 
the NOAA and Metop operational satellites for obtaining a longer data record and more frequent coverage. It can also be applied to other instruments that have the same combination of channels, for example the Advanced Technology Microwave Sounder (ATMS) onboard the Suomi-NPP satellite, or the Special Sensor Microwave Imager/Sounder (SSMI/S) onboard the Air Force F-16, F-17 and F-18 satellites. Fur- thermore, the approach we demonstrated in this study can be applied to IR/VIS sensors with the measurements collocated with CloudSat, such as Aqua Atmospheric Infrared Sounder (AIRS) and MODIS, to extend the sensitivity to lower IWP values and enhance the dynamic range of remote sensing of cloud ice from space. 


\section{Appendix A: Converting off-nadir $T_{\text {cir }}$ to nadir $T_{\text {cir }}$}

The collocation occurrences near outmost views are too few to form a statistically meaningful $T_{\mathrm{cir}}$-IWP relationship, as shown in Fig. 2. An alternative way is to seek a conversion factor such that the PDF of converted off-nadir $T_{\text {cir }}$ matches that of the nadir $T_{\mathrm{cir}}$, in which case the nadir $T_{\mathrm{cir}}$-IWP relationship can then be applied.

If the cloud layer can be assumed to be plane-parallel and is not completely opaque to $\mathrm{MHS}, \mathrm{PDF}_{\text {side }} \cdot \cos \zeta=\mathrm{PDF}_{\text {nadir }}$ roughly holds (thick solid lines in Fig. A1a), where $\zeta$ is the zenith angle. This relationship means that, with equal probability of seeing a cloud, the off-nadir cloud $T_{\text {cir }}$ is colder than that from the nadir view, mainly due to the longer integration length of cloud water paths. However, such a relationship begins to lose its validity as the ice clouds become opaque at oblique views. As shown in Fig. A1b, the PDF curves become much more flat at $T_{\text {cir }}=-100 \mathrm{~K}$ compared with those at $T_{\text {cir }}=-50 \mathrm{~K}$. A factor of $\cos (\zeta / 2.1)$ can roughly capture such a view dependency. In the most extreme case, where $T_{\text {cir }}$ saturates at all view angles, the PDFs should become independent of the view angle, where the factor can be set as $\cos (\zeta / \infty)$.

By defining $F=\cos (\zeta /$ fac $)$, we can convert the off-nadir $T_{\text {cir }}$ to the equivalent nadir $T_{\text {cir }}$ by multiplying the former by $F$, i.e.,

$\left.T_{\text {cir }}\right|_{\text {side }} \cdot F=\left.T_{\text {cir }}\right|_{\text {equivalent nadir }}$.

fac $=f\left(T_{\mathrm{cir}}, \mathrm{CH}\right)$ is a function of $T_{\mathrm{cir}}$ and the choice of channel number, which is estimated from the observation to follow such relationships:

$$
\begin{aligned}
& \operatorname{fac}(\mathrm{CH \# 2})= \\
& \begin{cases}0.7764 \cdot e^{-0.0077 T_{\mathrm{cir}}} & \text { if } T_{\mathrm{cir}}>-120 \mathrm{~K} \\
1 & \text { if } 0.7764 \cdot e^{-0.0077 T_{\mathrm{cir}}}<1 \\
100 & \text { if } T_{\mathrm{cir}} \leq-120 \mathrm{~K}\end{cases}
\end{aligned}
$$

$$
\begin{aligned}
& \operatorname{fac}(\mathrm{CH} 4)= \\
& \begin{cases}0.0013 \cdot e^{-0.1034 T_{\mathrm{cir}}} & \text { if } T_{\mathrm{cir}}>-120 \mathrm{~K} \\
1 & \text { if } 0.0013 \cdot e^{-0.1034 T_{\text {cir }}}<1 \\
100 & \text { if } T_{\text {cir }} \leq-80 \mathrm{~K}\end{cases}
\end{aligned}
$$

$$
\begin{aligned}
& \operatorname{fac}(\mathrm{CH} 5)= \\
& \begin{cases}0.8160 \cdot e^{-0.0098 T_{\mathrm{cir}}} & \text { if } T_{\mathrm{cir}}>-120 \mathrm{~K} \\
1 & \text { if } 0.8160 \cdot e^{-0.0098 T_{\mathrm{cir}}}<1 \\
100 & \text { if } T_{\mathrm{cir}} \leq-120 \mathrm{~K}\end{cases}
\end{aligned}
$$

\section{Appendix B: Correction of $\boldsymbol{T}_{\text {cir }}$ for $\mathrm{CH} \# 2$}

As shown by the black line in Fig. 1a, the PDF peak for $T_{\text {cir }}$ of $\mathrm{CH \#} 2$ is at $2 \mathrm{~K}$ instead of $0 \mathrm{~K}$ at the nadir view. Further
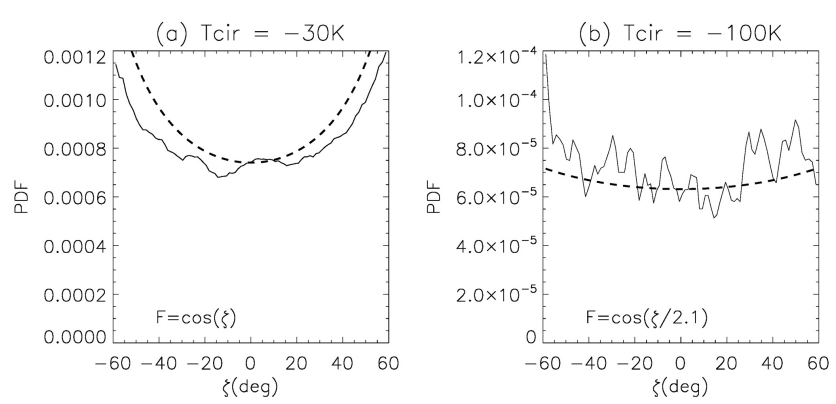

Figure A1. PDF of $T_{\text {cir }}$ in the range of $[-100,-99 \mathrm{~K}]($ a) and $[-50$, $-49 \mathrm{~K}](\mathbf{b})$ as a function of scan angle derived from a month of NOAA-18 MHS $T_{\text {cir }}$ data (December 2010). Thick solid curves are calculated from the mean PDF values averaged over the 10 nadirview FOVs divided by a factor of $\cos (\zeta / 2.1)$ (a) and $\cos \zeta$ (b), respectively, and are used to fit the observed PDF curves. $\zeta$ is the zenith angle.

examination of other months of $T_{\text {cir }}$ PDFs for this channel shows the same warm bias (named as $\Delta T$ ). At off-nadir views, $\Delta T$ becomes smaller, which follows the theoretical clear-sky limb-darkening curve $\Delta T_{\text {nadir }} \cdot \cos \zeta=\Delta T_{\text {side }}$. This means that the estimated $T_{\mathrm{ccr}}$ for clear skies has a systematic error at $157 \mathrm{GHz}$, which could originate from the inaccuracy of MERRA surface emissivity or errors inside CRTM. To account for this offset, all $T_{\text {cir }}$ values for $\mathrm{CH \# 2}$ are subtracted from this offset before carrying out the retrieval:

$T_{\text {cir }}(\mathrm{CH \#} 2)=T_{\text {cir }}(\mathrm{CH \#} 2)_{\text {calculated }}-2 \cdot \cos \zeta$

\section{Appendix C: Comparison with RTM simulations}

As one of the most important motivations of this work, it is worthwhile checking whether the existing operational RTMs can reproduce the observed $T_{\text {cir }}$-IWP relationship. Some research RTMs that have more sophisticated radiative transfer treatment produced comparable results with observations (e.g., Davis et al., 2007; Kulie et al., 2010). However, some of the major operational RTMs still have large biases in highfrequency microwave channels, which result in poor usage of cloudy/precipitating scenes observed by instruments such as MHS and SSMI. The goals of this exercise are hence to quantify operational model uncertainties and to determine how reliable these RTMs are for calculating cloudy-sky radiances as observed by satellite microwave channels/instruments. We would also like to identify possible causes of these model errors and develop a quick remedy for these operational models. Since this problem by itself is very complicated, it will only be touched briefly in the appendices here, and a paper to explore further details is underway.

Two popular models, CRTM and CRM, will serve as the representatives among different RTM variants. CRTM is widely used as the centerpiece of data assimilation in United States weather forecast systems, and CRM is used every day 
to generate MLS cloud products. In both models, three ice clouds are fed in one by one, with cloud bottoms at $7.5 \mathrm{~km}$ and cloud tops at 10, 12 and $14 \mathrm{~km}$, respectively. Two cloud shapes (convection with anvil cloud top; Gaussian shape) are tested. Since their results differ little, the first cloud shape is applied to all following studies. US standard atmosphere in the tropics is used as the background atmosphere. For the cloud droplet size distribution, CRM has several options. Only McFarquhar-Heymsfield (MH) and Gamma distributions are tested with different combinations of parameter values. MH distribution was applied to deliver MLS IWC products (Wu et al., 2009), and Gamma size distribution was assumed for CloudSat ice water product retrievals (Austin et al., 2009). In CRTM, only the cloud ice effective radius is tunable with fixed-width Gamma size distribution assumption. Both models and the observation are compared at nadir view only.

Comparing $T_{\text {cir }}$ responses from different channels to the same cloud is a straightforward yet very effective way of presenting many of the differences. As one can see from Fig. $\mathrm{C} 1 \mathrm{a}, \mathrm{CH} 2$ should have a larger response to thin and medium thick clouds, and the penetration depths of $\mathrm{CH \# 2}$ and $\mathrm{CH} \# 5$ are about the same when they encounter dense and thick clouds. Raw $T_{\mathrm{B}}$ from the two channels showed the same features (not shown). CRTM produces almost identical reposes for $\mathrm{CH} \# 2$ and $\mathrm{CH} \# 5$, both of which are however too weak compared with the observation (triangles). CRM produces comparable dynamical ranges of $T_{\text {cir }}$, with an effective radius of $160 \mu \mathrm{m}$ and a width parameter of 2 (refer to Evans et al. (1998) for the format of the Gamma distribution), but it always generates a weaker response for $\mathrm{CH} 2$, contradicting the observation (crosses), while the $T_{\text {cir }}$-IWP relationship for $\mathrm{CH}$ 5 is simulated quite well. The main caveat of CRM is that it only considers scattering while ignoring the ice emission. The observed $\mathrm{CH} 2 / \mathrm{CH} \# 5 T_{\text {cir }}$ ratio suggests that ice cloud emission offsets as much as $30 \%$ of the cloud scattering impact for thin and medium thick clouds, while cloud scattering dominates for dense and thick clouds. Moreover, liquid droplets in mixed-phase clouds could contribute more to the emissions and further reduce the $\mathrm{CH} H 5 T_{\text {cir }}$ response. That may explain the difference between CRTM and the observation.

The models simulate the observed $T_{\text {cir }}$ ratio between $\mathrm{CH \# 4}$ and $\mathrm{CH} \# 5$ better, as shown in Fig. C1b. Nevertheless, models tend to over-predict the $\mathrm{CH \#} 4$ response. Because $\mathrm{CH \#} 4$ is closer to the $183.3 \mathrm{GHz}$ water vapor absorption line, it is
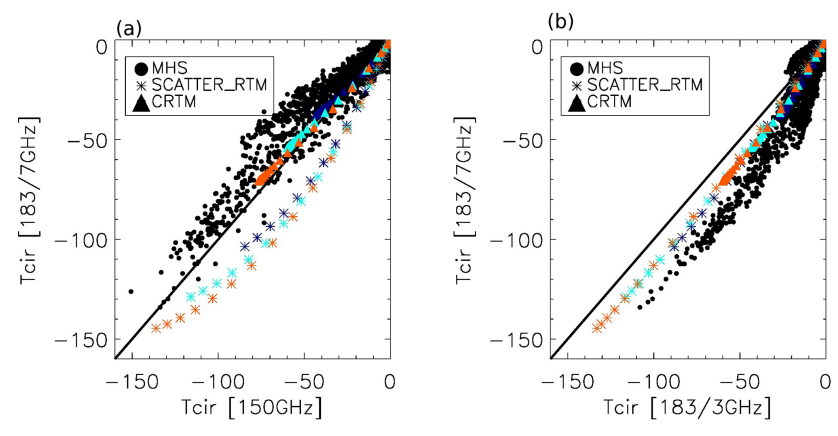

Figure C1. Scatter plots of $T_{\text {cir }}$ relationships between $\mathrm{CH \# 2}$ and $\mathrm{CH \# 5}$ (a), and $\mathrm{CH \# 4}$ and $\mathrm{CH \# 5}$ (b) from observed $T_{\text {cir }}$ at MHS nadir view (black dots), simulated $T_{\text {cir }}$ from CRTM (colored triangles) and from CRM (colored stars). Blue/cyan/red colors represent cloud layer with tops at 10,12 and $14 \mathrm{~km}$ and bottoms at $7.5 \mathrm{~km}$ in the simulations.

more sensitive to water vapor variations than $\mathrm{CH} \# 5$. Therefore, the air above the cloud top might have been drier than the ambient air to lead to a smaller magnitude of $\mathrm{CH \# 4} T_{\text {cir }}$. This derivation is supported by some observational evidences for deep convective clouds (e.g., Chae et al., 2011). Again, CRTM overall produces weaker $T_{\text {cir }}$, probably due to the heavy extrapolation from thin cloud LUT to thicker clouds, and the narrow fixed-width Gamma size distribution.

To summarize, the two widely used operational RTMs are far behind the empirical model in capturing the observed $T_{\text {cir-IWP relationships for tropical ice clouds. For relatively }}$ thick ice clouds that should produce $30 \mathrm{~K}$ or more $T_{\mathrm{B}}$ depressions, the warm bias of CRTM easily exceeds $100 \%$, making it impossible to assimilate the observed thick/precipitation ice clouds from high-frequency microwave instruments. For CRM, the biases can be as large as $50 \%$ for the $150 \mathrm{GHz}$ channel. Some plausible explanations are given to explain the observed model discrepancies, which include but are not limited to the wrong extrapolation of the look-up table of ice clouds, oversight of emission from liquid droplets and ice particles, indifference to humidity above clouds and ambient air, and too narrow a width of Gamma size distribution. One should be advised that Gamma distribution is not indicated as the best cloud ice particle size distribution. Rather, it reflects the inter-model consistency between the two RTMs and the original assumptions made for CloudSat IWP retrievals. Due to the popularity of these two RTMs, this part of work is of much interest to a broad community. 
Acknowledgements. This work is performed at the NASA Goddard Space Flight Center with support from the NASA NNH10ZDA001N-ESDRERR (Earth System Data Records Uncertainty Analysis) project. The authors are grateful to S. Buehler, V. John, I. Moradi, and S. Wong for helpful discussions and comments. We thank the two anonymous referees for their reviews. AAPP is provided by the EUMETSAT network of satellite application facilities.

Edited by: D. Cimini

\section{References}

Amiridis, V., Wandinger, U., Marinou, E., Giannakaki, E., Tsekeri, A., Basart, S., Kazadzis, S., Gkikas, A., Taylor, M., Baldasano, J., and Ansmann, A.: Optimizing CALIPSO Saharan dust retrievals, Atmos. Chem. Phys., 13, 12089-12106, doi:10.5194/acp-1312089-2013, 2013.

Atkinson, N. C.: Calibration, monitoring and validation of AMSUB, Adv. Space. Res., 28, 117-126, 2001.

Austin, R. T., Heymsfield, A. J., and Stephens, G. L.: Retrievals of ice cloud microphysical parameters using the CloudSat millimeter-wave radar and temperature, J. Geophys. Res., 114, D00A23, doi:10.1029/2008JD010049, 2009.

Arriaga, A.: Technical memorandum No.5: Microwave Humidity Sounder (MHS) simulations with a radiative transfer model, EUMETSAT technical report, 2000.

Buehler, S. A., Kuvatov, M., and John, V. O.: Scan asymmetries in AMSU-B data, Geophys. Res. Lett., 32, L24810, doi:10.1029/2005GL024747, 2005.

Chae, J. H., Wu, D. L., Read, W. G., and Sherwood, S. C.: The role of tropical deep convective clouds on temperature, water vapor, and dehydration in the tropical tropopause layer (TTL), Atmos. Chem. Phys., 11, 3811-3821, doi:10.5194/acp-11-38112011, 2011.

Chahine, M. T.: The hydrological cycle and its influence on climate, Nature, 359, 373-380, 1992.

Chen, F. W. and Staelin, D. H.: AIRS/AMSU/HSB precipitation estimates, IEEE T. Geosci. Remote, 41, 410-417, doi:10.1109/TGRS.2002.808322, 2003.

Chen, W.-T., Woods, C. P., Li, J.-L. F., Waliser, D. E., Chern, J.D., Tao, W.-K., Jiang, J. H., and Tompkins, A. M.: Partitioning CloudSat Ice Water Content for Comparison with UpperTropospheric Ice in Global Atmospheric Models, J. Geophys. Res., 116, D19206, doi:10.1029/2010JD015179, 2011.

Davis, C. P., Evans, K. F., Buehler, S. A., Wu, D. L., and Pumphrey, H. C.: 3-D polarised simulations of space-borne passive $\mathrm{mm} / \mathrm{sub}-$ mm midlatitude cirrus observations: a case study, Atmos. Chem. Phys., 7, 4149-4158, doi:10.5194/acp-7-4149-2007, 2007.

Eliasson, S., Buehler, S. A., Milz, M., Eriksson, P., and John, V. O.: Assessing observed and modelled spatial distributions of ice water path using satellite data, Atmos. Chem. Phys., 11, 375391, doi:10.5194/acp-11-375-2011, 2011.

Evans, K. F., Walter, S. J., Heymsfield, A. J., and Deeter, M. N.: Modeling of Submillimeter Passive Remote Sensing of Cirrus Clouds, J. Appl. Meteorol., 37, 184-205, 1998.

Ferraro, R.: NOAA AIWP algorithm website, available at: http://www.star.nesdis.noaa.gov/corp/scsb/mspps/algorithms. html\#AIWP(last access: 23 June 2014), 2007.
Gong, J. and Wu, D. L.: View-angle dependent AIRS cloudiness and radiance variance: analysis and interpretation, J. Geophys. Res., 118, 2327-2339, doi:10.1002/jgrd.50120, 2013.

Holl, G., Buehler, S. A., Rydberg, B., and Jiménez, C.: Collocating satellite-based radar and radiometer measurements - methodology and usage examples, Atmos. Meas. Tech., 3, 693-708, doi:10.5194/amt-3-693-2010, 2010.

Holl, G., Eliasson, S., Mendrok, J., and Buehler, S. A.: SPARE-ICE: Synergistic ice water path from passive operational sensors, J. Geophys. Res., 119, 1504-1523, 2014.

John, V. O., Holl, G., Buehler, S. A., Candy, B., Saunders, R. W., and Parker, D. E.: Understanding inter-satellite biases of microwave humidity sounders using global SNOs, J. Geophys. Res., 117, D02305, doi:10.1029/2011JD016349, 2012.

John, V. O., Holl, G., Atkinson, N., and Buehler, S. A.: Monitoring scan asymmetry of microwave humidity sounding channels using simultaneous all angle collocations (SAACs), J. Geophys. Res., 118, 1536-1545, doi:10.1002/jgrd.50154, 2013.

Kahn, B. H., Chahine, M. T., Stephens, G. L., Mace, G. G., Marchand, R. T., Wang, Z., Barnet, C. D., Eldering, A., Holz, R. E., Kuehn, R. E., and Vane, D. G.: Cloud type comparisons of AIRS, CloudSat, and CALIPSO cloud height and amount, Atmos. Chem. Phys., 8, 1231-1248, doi:10.5194/acp-8-1231-2008, 2008.

Kulie, M. S., Bennartz, R., Greenwald, T. J., Chen, Y., and Weng, F.: Uncertainties in Microwave Properties of Frozen Precipitation: Implications for Remote Sensing and Data Assimilation, J. Atmos. Sci., 67, 3471-3487, doi:10.1175/2010JAS3520.1, 2010.

Lamquin, N., Stubenrauch, C. J., and Pelon, J.: Upper tropospheric humidity and cirrus geometrical and optical thickness: relationships inferred from 1 year of collocated AIRS and CALIPSO data, J. Geophys. Res., 113, D00A08, doi:10.1029/2008JD010012, 2008.

Li, J.-L., Li, F., Waliser, D. E., Chen, W.-T., Guan, B., Kubar, T., Stephens, G., Ma, H.-Y., Deng, M., Donner, L., Seman, C., and Horowitz, L.: An observationally based evaluation of cloud ice water in CMIP3 and CMIP5 GCMs and contemporary reanalyses using contemporary satellite data, J. Geophys. Res., 117, D16105, doi:10.1029/2012JD017640, 2012.

Liu, Q. and Weng, F.: Advanced Doubling-Adding Method for Radiative Transfer in Planetary Atmospheres, J. Atmos. Sci., 63, 3459-3465, 2006.

Livesey, N. J., Snyder, W. V., Read, W. G., and Wagner, P. A.: Retrieval algorithms for the EOS Microwave Limb Sounder (MLS), IEEE T. Geosci. Remote., 44, 1144-1155, doi:10.1109/TGRS.2006.872327, 2006.

Meyer, K., Yang, P., and Gao, B.-C.: Tropical ice cloud optical depth, ice water path, and frequency fields inferred from the MODIS level-3 data, Atmos. Res., 85, 171-182, doi:10.1016/j.atmosres.2006.09.009, 2007.

McFarquhar, G. M. and Heymsfield, A. J.: Parameterization of tropical cirrus ice crystal size distributions and implications for radiative transfer: results from CEPEX, J. Atmos. Sci., 54, 2187-2200, doi:10.1175/15200469(1997)054<2187:POTCIC>2.0.CO;2, 1997.

McNally, A. P., Watts, P. D., Smith, J. A., Engelen, R., Kelly, G. A., Thepaut, J. N., and Matricardi, M.: The assimilation of AIRS radiance data at ECMWF, Q. J. Roy. Meteorol. Soc., 132, 935957, 2006. 
Protat, A., Bouniol, D., Delanoe, J., O’Connor, E., May, P. T., PlanaFattori, A., Hasson, A., Gorsdorf, U., and Heymsfield, A. J.: Assessment of Cloudsat Reflectivity Measurements and Ice Cloud Properties Using Ground-Based and Airborne Cloud Radar Observations, J. Atmos. Ocean. Tech., 26, 1717-1741, 2009.

Pulliainen, J. and Hallikainen, M.: Retrieval of Regional Snow Water Equivalent from Space-Borne Passive Microwave Observations, Remote. Sens. Environ., 75, 76-85, 2001.

Ramaswamy, V. and Ramanathan, V.: Solar absorption by cirrus clouds and the maintenance of the tropical upper troposphere thermal structure, J. Atmos. Sci., 46, 2293-2310, 1989.

Richter, J. and Rasch, P.: Effects of convective momentum transport on the atmospheric circulation in the Community Atmosphere Model, version 3, J. Climate, 21, 1487-1499, 2008.

Riedi, J., Goloub, P., and Marchand, R. T.: Comparison of POLDER cloud phase retrievals to active remote sensors measurements at the ARM SGP site, Geophys. Res. Lett., 28, 2185-2188, 2001.

Rodgers, C. D.: Inverse methods for atmospheric science, theory and practice, World Scientific, 2000.

Seo, E.-K. and Liu, G.: Determination of 3-D cloud ice water contents by combining multiple data sources from satellite, ground radar, and a numerical model, J. Appl. Meteorol., 45, 1494-1504, doi:10.1175/JAM2430.1, 2006.

Soden, B. J.: Tracking upper tropospheric water vapor radiances: A satellite perspective, J. Geophys. Res., 103, 17069-17081, doi:10.1029/98JD01151, 1998.

Stephens, G. L., Tsay, S. C., Stackhouse, P. W., and Flatau, P. J.: The relevance of the microphysical and radiative properties of cirrus clouds to climate and climatic feedback, J. Atmos. Sci., 47, p. 1742, 1990.

Su, H., Jiang, J. H., Stephens, G. L., Vane, D. G., and Livesey, N. J.: Radiative effects of upper tropospheric clouds observed by Aura MLS and CloudSat, Geophys. Res. Lett., 36, L09815, doi:10.1029/2009GL037173, 2009.

Sun, B., Reale, A., Seidel, D. J., and Hunt, D. C.: Comparing radiosonde and COSMIC atmospheric profile data to quantify differences among radiosonde types and the effect of imperfect collocation on comparison statistics, J. Geophys. Res., 115, D23104, doi:10.1029/2010JD014457, 2010.
Waliser, D. E., Li, J.-L. F., Woods, C. P., Austin, R. T., Bacmeister, J., Chern, J., Genio, A. D., Jiang, J. H., Kuang, Z., Meng, H., Minnis, P., Platnick, S., Rossow, W. B., Stephens, G. L., SunMack, S., Tao, W.-K., Tompkins, A. M., Vane, D. G., Walker, C., and Wu, D.: Cloud ice: A climate model challenge with signs and expectations of progress, J. Geophys. Res., 114, D00A21, doi:10.1029/2008JD010015, 2009.

Wang, L.-K., Wu, X.-Q., Goldberg, M., Cao, C.-Y., Li, Y.-P., and Sohn, S.-H.: Comparison of AIRS and IASI radiances using GEOS imagers as transfer radiometers toward climate data record, J. Appl. Meteor. Clim., 49, 478-492, 2010.

Weng, F., Zhao, L., Ferraro, R. R., Poe, G., Li, X., and Grody, N. C.: Advanced microwave sounding unit cloud and precipitation algorithms, Radio Sci., 38, 8068, doi:10.1029/2002RS002679, 2003.

Wu, D. L. and Jiang, J. H.: EOS MLS Algorithm Theoretical Basis for Cloud Measurements, Technical Report, Jet Propulsion Laboratory, D-19299/CL\#04-2160, ATBD-MLS-06, 2004.

Wu, D. L., Read, W. G., Dessler, A. E., Sherwood, S. C., and Jiang, J. H.: UARS/MLS Cloud Ice Measurements: Implications for $\mathrm{H}_{2} \mathrm{O}$ Transport near the Tropopause, J. Atmos. Sci., 62, 518-530, 2005.

Wu, D. L., Austin, R. T., Deng, M., Durden, S. L., Heymsfield, A. J., Jiang, J. H., Lambert, A., Li, J.-L., Livesey, N. J., McFarquhar, G. M., Pittman, J. V., Stephens, G. L., Tanelli, S., Vane, D. G., and Waliser, D. E.: Comparisons of global cloud ice from MLS, CloudSat, and correlative data sets, J. Geophys. Res., 114, D00A24, doi:10.1029/2008JD009946, 2009.

Wu, D. L., Lambert, A., Read, W. G., Eriksson, P., and Gong, J.: MLS and CALIOP cloud ice measurements in the upper troposphere: A constraint from microwave on cloud microphysics, J. Appl. Meteorol. Clim., 53, 157-165, doi:10.1175/JAMC-D-13041.1, 2014.

Zhao, L. and Weng, F.: Retrieval of ice cloud parameters using the Advanced Microwave Sounding Unit (AMSU), J. Appl. Meteorol., 41, 384-395, 2002. 